\title{
Evolution of the spatial structure of a thin phytoplankton layer into a turbulent field
}

\author{
Zhankun Wang*, Louis Goodman
}

School of Marine Science and Technology (SMAST), University of Massachusetts, Dartmouth, 706 South Rodney French Blvd, New Bedford, Massachusetts 02744, USA

\begin{abstract}
We examined the role of turbulence on the evolution of the spatial structure of a thin phytoplankton layer. The approach used the small autonomous underwater vehicle (AUV), T-REMUS (turbulence-remote environmental measuring units), which is equipped with optical and physical micro- and fine-scale sensors. As part of the Layered Organization in the Coastal Ocean (LOCO) experiment, T-REMUS was deployed in a very shallow region of Monterey Bay, California, USA, over an $8 \mathrm{~h}$ nighttime period in summer 2006. A thin layer of chlorophyll a (chl a) was observed throughout the entire experimental period. The center of the thin layer deepened with time, crossed isotherms, and then settled into a strong turbulence layer. This result is in sharp contrast to previous conclusions that biological thin layers only occur in regions of weak turbulence. Our observations indicated that the turbulence field itself was constrained to be in a thin layer by the surrounding strong density stratification. The chl a material, acting as a passive Lagrangian tracer, became embedded within the turbulent field. With time, both the turbulent field and the embedded chl $a$ thin layer were observed to collapse vertically.
\end{abstract}

KEY WORDS: Thin layers · Turbulent mixing $\cdot$ Chlorophyll a AUV $\cdot$ Monterey Bay · Sinking • Vertical dispersion and contraction

Resale or republication not permitted without written consent of the publisher

\section{INTRODUCTION}

Thin layers of phytoplankton, zooplankton, marine snow, and even bacteria and viruses (Donaghay et al. 1992, MacIntyre et al. 1995, McManus et al. 2003) now appear to be common phenomena in the coastal ocean. These thin layers typically range from a few $\mathrm{cm}$ to a few $\mathrm{m}$ in vertical extent and $10 \mathrm{~s}$ of $\mathrm{m}$ to $10 \mathrm{~s}$ of $\mathrm{km}$ in horizontal extent, persisting from hours to days (Dekshenieks et al. 2001, Alldredge et al. 2002, Rines et al. 2002, McManus et al. 2003, 2005). During the daytime they tend to occur in the upper part of the water column within the euphotic zone, but they can also occur at nighttime, though typically somewhat deeper. Donaghay et al. (1992) have argued that traditional sampling tools such as plankton nets and bottle samples do not have sufficient vertical spatial resolution to resolve many thin layer structures. This has resulted in vertical spatial aliasing and enhanced error variance of estimated thin layer biomass. In the last decade, with the advent of very high resolution optical and acoustic pro- filing techniques (Zaneveld et al. 1992, Holliday et al. 1998, Sullivan et al. 2005), a more accurate estimate of the number and biomass of the thin layers can now be made.

For example, in the mid-1990s the state of the art high frequency sonar system (Holliday et al. 1998) had a vertical spatial resolution of $2 \mathrm{~m}$ for the estimation of zooplankton thin layer abundance. By increasing the number of acoustic frequencies used, the vertical spatial resolution of the most recent high frequency acoustic observing system, TAPS, is now $<0.2 \mathrm{~m}$ (Holliday et al. 2003). Chlorophyll a (chl a) thin layer data, collected by the T-REMUS (turbulence-remote environmental measuring units) vehicle using a $5^{\circ}$ yoyo deployment, have a vertical resolution of $\sim 0.1 \mathrm{~m}$. A vertical resolution of $0.02 \mathrm{~m}$ has been achieved by the fixed slow drop profiler, ORCAS (Donaghay 2004, Sullivan et al. 2005). These latter 2 platforms as well as some similar instruments not only can now resolve the smallest vertical extent of thin layers but also have onboard companion sensors which can measure the sur- 
rounding local fine- and microstructure physical fields in which the thin layers are embedded.

Thin layers have now been observed in a variety of coastal marine environments, including a shallow fjord (East Sound, WA, USA i Alldredge et al. 2002), the continental shelf (Monterey Bay, CA, USA; McManus et al. 2005), and an enclosed sea (Baltic Sea; Nielson et al. 1990). Although recent advances in high resolution optical and acoustical sensors have provided evidence of thin layers at multiple coastal ocean sites (McManus et al. 2005), little direct research has occurred on the role of the very smallest scale physical processes on thin layers. One of the principal objectives of the Layered Organization in the Coastal Ocean (LOCO) experiment was to examine this role.

Because of the small size of phytoplankton and their limited mobility, turbulence is thought to have a significant effect on their biodynamics and on the behavior of predatory organisms residing nearby (Donaghay \& Osborn 1997, Osborn 1998). Laboratory studies have shown that turbulence can change the size and growth rate of phytoplankton (Sullivan \& Swift 2003), change the density of local nutrients and wastes around them (Lazier \& Mann 1989), and increase or decrease plankton encounter rates with nutrients (Rothschild \& Osborn 1988, Seuront et al. 2001). A recent study by Stacey et al. (2007) employed a model of thin layer formation and maintenance dynamics. In their model, they examined the evolution of biological particles within thin layers in terms of a balance between vertical dispersion and various advective mechanisms, i.e. horizontal shear, particle buoyancy, and motility. Stacey et al. (2007) concluded that in real oceanic conditions, these mechanisms can result in either a convergence or divergence of these particles.

In situ simultaneous observations of turbulence and plankton distribution are very limited. Some work has been performed by estimating turbulent mixing from temperature microstructure measurements (McManus et al. 2003). It has been hypothesized that weak or moderate turbulence would be expected in thin layers. Analyzing 120 profiles collected from 3 cruises in 1996 in East Sound, Dekshenieks et al. (2001) concluded that thin layers appeared not to occur under strong turbulent conditions, which they defined by the criteria of the gradient Richardson number $\left(\mathrm{Ri}_{\mathrm{g}}\right)<0.25$. It should be noted that this is an indirect inference of turbulence (Thorpe 2005). In a study on marine snow thin layers (Alldredge et al. 2002), the turbulent kinetic energy (TKE) dissipation rate, $\varepsilon$, was estimated using the spectra expected for temperature microstructure (Dillon \& Caldwell 1980). It was observed that dissipation rate in the thin layer was very low, $\varepsilon<10^{-8} \mathrm{~W} \mathrm{~kg}^{-1}$. However, such estimates of dissipation rate using temperature microstructure spectra involve a number of assump- tions (Luketina \& Imberger 2001). Moreover, since the molecular diffusivity of temperature is 7 times smaller than that of momentum, temperature microstructure may not necessarily be associated with velocity microstructure and may, in fact, be a reflection of a decaying remnant of a stratified turbulent field (Sherman \& Davis 1995). In addition, because of the finite response time of the fastest available temperature sensors, the temperature microstructure field is typically not resolvable to a sufficiently small scale to perform an accurate estimate (Luketina \& Imberger 2001). Finally, for turbulence measurements to be useful they must be collocated within the distance of the largest scale of the turbulent field, which in many cases in coastal regimes with very strong stratification is less than $1 \mathrm{~m}$.

In the present study we examined a set of measurements of chl $a$ and optical scattering (470 and $700 \mathrm{~nm}$ ) thin layers made concurrently and in the same location as that of turbulence and fine-scale measurements of temperature, salinity, and velocity. Our approach used the T-REMUS autonomous underwater vehicle (AUV) in a $5^{\circ}$ yoyo mode. This resolves the processed optical and physical quantities to a vertical scale of $0.1 \mathrm{~m}$ and a horizontal scale of $150 \mathrm{~m}$. The T-REMUS also directly estimates the turbulent dissipation rate, a key quantity used to derive a number of parameters relevant to the biodynamics of the thin layer evolution. We used the criteria of Dekshenieks et al. (2001) for the definition of thin layers, namely, that the magnitude of an optically based signal must be 3 times greater than its background value. In a recent manuscript Goodman \& Wang (2008) presented a detailed discussion of the nature of the turbulent field in the same experimental site. They observed that a strong turbulence field occurred principally: (1) near a surface mixing region associated with a 'micro' front; (2) as a result of an internal wave train; and (3) in the bottom boundary layer. The present study focuses on the biological aspects of the same dataset, with emphasis on the relationship of the evolution of a thermocline based thin layer to its local turbulent field, the latter produced by mechanism (2), cited above.

\section{MATERIALS AND METHODS}

Experimental overview. The experiment was performed as a part of the 2006 LOCO field program sponsored by the Office of Naval Research (ONR). It took place in a shallow bight in northern Monterey Bay, (Fig. 1a), from 19:00 h, 17 July 2006 to 03:00 h Pacific Daylight Time (PDT), 18 July 2006. Bathymetry within the experimental site (Fig. 1b) slopes uniformly from 16 to $23 \mathrm{~m}$ across-shelf. The data was collected from a T-REMUS vehicle operated in a $5^{\circ}$ yoyo mode. The 


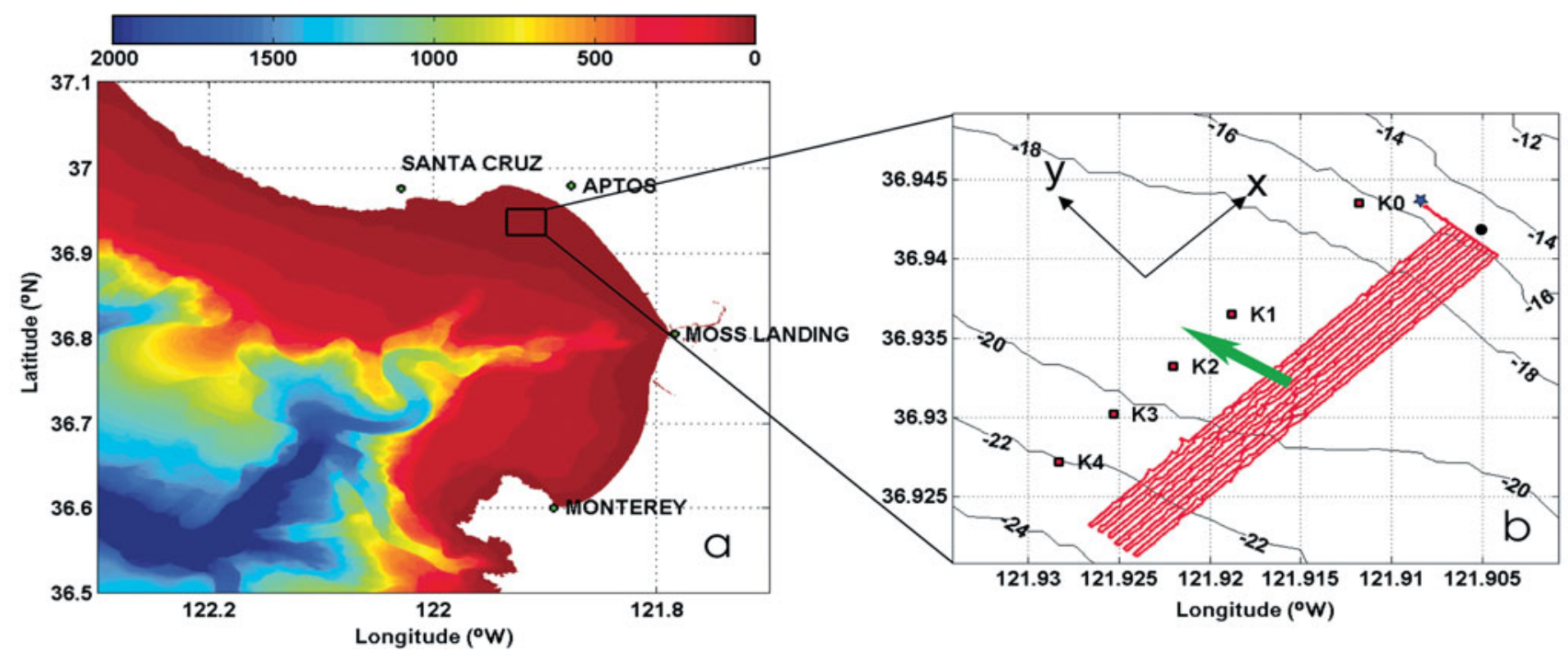

Fig. 1. (a) Sea floor topography in Monterey Bay, CA, USA. The horizontal scale is water depth (m). Open rectangle: site of LOCO 2006 experiments. (b) Details of the autonomous underwater vehicle (AUV) T-REMUS track (red lines) in the northern bight of Monterey Bay, in a study conducted from 19:00 h Pacific Daylight Time (PDT) on 17 July to 03:00 h PDT on 18 July 2006. Each parallel red line has an across-isobath distance of $\sim 2500 \mathrm{~m}$. Black contour lines are water depth in $\mathrm{m}$. The AUV was programmed to start and end at the same location $(\star)$. Green arrow: direction of the vertically averaged current during the $8 \mathrm{~h}$ experiment; $(\bullet)$ reference point used to calculate the AUV offshore distance. K0 to K4 (K-line) are 5 fixed mooring stations deployed by other LOCO groups

AUV tracks consisted of 12 lines, termed 'legs', that ran parallel to the fixed LOCO observatory stations, K0 to K4 (Fig. 1b). Each leg survey was 40 min in length, and there were, on average, 16 yoyo profiles per leg. The non de-tided mean flow direction shown by the green arrow in Fig. 1b is along isobath with the vertically averaged current obtained by the acoustic Doppler current profiles (ADCP), approximately $0.1 \mathrm{~m} \mathrm{~s}^{-1}$. The vehicle upper depth limit was set at $z=1 \mathrm{~m}$ from the surface, and the lower depth limit at $z=4 \mathrm{~m}$ above the bottom. Traveling at $1.2 \mathrm{~m} \mathrm{~s}^{-1}$, the AUV covered a total horizontal distance of $34.5 \mathrm{~km}$ in $8 \mathrm{~h}$ and collected a total of 193 vertical profiles with an average horizontal sampling distance of $150 \mathrm{~m}$.

Monterey Bay, located between $36.55^{\circ} \mathrm{N}$ and $37.00^{\circ} \mathrm{N}$ (Fig. 1a), is the largest bay along the west coast of the United States. It is semi-enclosed, with very restricted freshwater input. During the 2006 LOCO experiments, there was almost no precipitation. Thus, the effect of terrestrial input can be ignored, resulting in weak salinity variability and density being principally determined by temperature. During the experiment, the wind speed was very low and the air-sea interaction weak. The overall current field in the experimental site tended to be towards the northwest and parallel to the isobaths, thus perpendicular to the AUV tracks. However, there was an across-isobath, offshore-directed, near-surface current which advected near-surface warm water from onshore to offshore. The tidal current was relatively weak, estimated to be less than $5 \mathrm{~cm} \mathrm{~s}^{-1}$ throughout the experiment (Mc-
Manus et al. 2005). Maximum tidal displacement during the experiment was $1.5 \mathrm{~m}$, changing from high to low during the experiment. Using data from a thermistor chain at fixed Stn K1, Goodman \& Wang (2008) found, during the time of the experiment, the presence of 2 large amplitude isolated internal solitary waves, the leading edge of which reached the T-REMUS at approximately 22:00 h PDT, 17 July 2006. Following these 2 isolated internal waves, starting at 23:00 h PDT, 17 July 2006 and lasting until the end of the experiment, was a nearly continuous downwardly displaced internal wave train. It was this internal wave train which was associated with occurrence of the strong, midwater column, thermocline-based turbulence in which a chl a thin layer, described below, was embedded.

Observational approach. T-REMUS is an extended standard REMUS 100 vehicle, equipped with the Rockland Microstructure Measurement System (RMMS), a WET Labs Combination Spectral Backscattering Meter/ Chlorophyll Fluorometer-ECO BB2F, a Seabird 49 FASTCAT CTD, an upward and downward looking 1.2 $\mathrm{MHz}$ RDI ADCP, and a variety of 'hotel' sensors monitoring the 6 degree of freedom AUV motion (Fig. 2).

Operating the T-REMUS in a $5^{\circ}$ yoyo mode, this suite of sensors resulted in a vertical resolution of $0.1 \mathrm{~m}$ for estimates of density, chl $a$, and optical backscattering, and $0.5 \mathrm{~m}$ for the TKE dissipation rate, $\varepsilon$. (See MacDonald et al. 2007 for a description of averaging techniques.) The mean horizontal sampling distance between successive profiles was $150 \mathrm{~m}$. The turbulent sensors on the T-REMUS vehicle are the standard sen- 


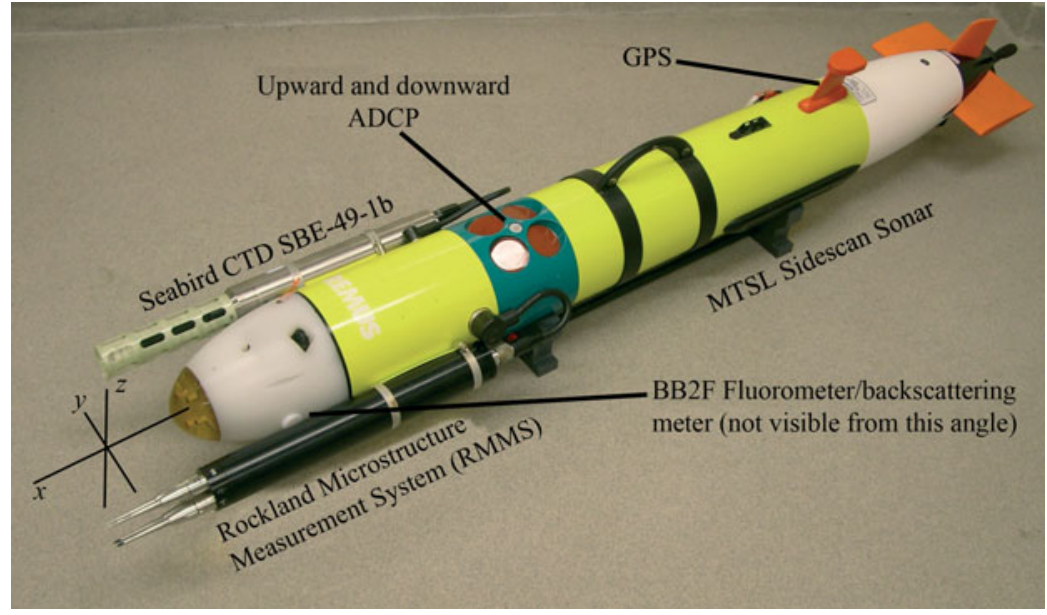

Fig. 2. The SMAST T-REMUS autonomous underwater vehicle (length: $2 \mathrm{~m}$; mass: $63 \mathrm{~kg}$ ). Vehicle-based sensors are indicated. ADCP: acoustic Doppler current profiler

sors for directly estimating TKE dissipation rate, namely the turbulent shear probe, originally developed by Siddon (1965) and widely used in the oceanographic community in vertical microstructure (turbulence) profilers (Lueck et al. 2002).

Using the turbulent dissipation rate, $\varepsilon$, and the local value of the buoyancy frequency, $N$, obtained from the FASTCAT CTD, we can estimate the buoyancy Reynolds number:

$$
\operatorname{Re}_{\mathrm{b}}=\frac{\varepsilon}{v N^{2}}=\left(\frac{N^{-1}}{\tau_{\mathrm{s}}}\right)^{2}
$$

where $v=10^{-6} \mathrm{~m}^{2} \mathrm{~s}^{-1}$ is the kinematic molecular viscosity and $N$ the buoyancy frequency defined by:

$$
N=\sqrt{-\frac{g}{\rho_{0}} \frac{\partial \rho}{\partial z}}
$$

where $g=9.8 \mathrm{~m} \mathrm{~s}^{-2}$ is the gravitational acceleration, $\rho$ and $\rho_{0}$ are the potential and reference densities of water, respectively, and $z$ the water depth. Note that in Eq. (1) we have expressed the $\mathrm{Re}_{\mathrm{b}}$ in terms of the ratio of $\tau_{\mathrm{s}}=(\varepsilon / v)^{-1 / 2}$, the characteristic time scale associated with the turbulent shear, and $N^{-1}$, the buoyancy period. The buoyancy Reynolds number $\mathrm{Re}_{\mathrm{b}}$ allows quantification of the intensity of the turbulent field. When $\mathrm{Re}_{\mathrm{b}}>200$, the turbulent field is fully developed and isotropic (Yamazaki \& Osborn 1990); we will use the term 'strong turbulence' to refer to that condition. When $\mathrm{Re}_{\mathrm{b}}<20$, stratification is sufficiently strong such that turbulence ceases to exist (Yamazaki \& Osborn 1990). Using the dissipation rate $\varepsilon$ and the buoyancy frequency $N, 2$ other key turbulence based physical variables can be estimated, eddy diffusivity, $\kappa_{\rho}$, and turbulent velocity scale, $w^{\prime}$, given as:

$$
\kappa_{\rho}=\Gamma \varepsilon / N^{2}=\Gamma v \operatorname{Re}_{\mathrm{b}}
$$

and

$$
W^{\prime}=(\varepsilon / N)^{1 / 2}
$$

where $\Gamma$ is the mixing efficiency, typically taken to be 0.2 (Osborn 1980). Note that $w^{\prime}$ given by Eq. (3) is sometimes referred to as the buoyancy or Ozmidov velocity scale. Substituting $\Gamma=$ 0.2 and $v=10^{-6} \mathrm{~m}^{2} \mathrm{~s}^{-1}$ into Eq. (2), we obtain a relationship between eddy diffusivity and buoyancy Reynolds number, namely $\kappa_{\rho}=2 \times 10^{-7} \operatorname{Re}_{\mathrm{b}}\left(\mathrm{m}^{2} \mathrm{~s}^{-1}\right)$. Using the criteria of $\operatorname{Re}_{\mathrm{b}}>200$ then results in a range of diffusivity values of $\kappa_{p}>4 \times 10^{-5} \mathrm{~m}^{2} \mathrm{~s}^{-1}$ for strong turbulence.

The turbulent velocity scale estimate $W^{\prime}$ is useful for comparison of the local instantaneous fluid flow speed to the phytoplankton motility speed, the latter of which can result from either self propulsion, in the case of dinoflagellates, or from sinking, in the case of diatoms. Phytoplankton will tend to follow the movement of the turbulence flow when its motility speed is much less than that of the turbulent velocity scale.

The WET Labs BB2F sensor system outputs are chl a fluorescence and optical backscattering at 470 and $700 \mathrm{~nm}$. The chl a signal can be expected to be related directly to an estimate of the phytoplankton biomass (Wolf \& Woods 1988). Diatoms and dinoflagellates are the 2 major types of phytoplankton in Monterey Bay. Both have the ability to cross isopycnal surfaces either by sinking or by self propulsion. The dinoflagellates have considerable motility and some can move with speeds up to several $\mathrm{m} \mathrm{h}^{-1}$. Diatoms have weaker motility, but due to a variety of complex biochemical processes, have a density which can vary with depth resulting in a varying terminal sinking velocity. In addition, non-living organic and inorganic particles were also found to occur at the LOCO experimental site. Sullivan et al. (2005) have suggested that the ratio of optical backscattering intensity to the chl a fluorescence can be used to discriminate living phytoplankton from non-living particulate debris. Although mineral and dense detrital particles typically backscatter more light than living phytoplankton, certain phytoplankton such as coccolithophorids can also produce significant backscatter. However, these organisms do not occur regularly in Monterey Bay (J. Sullivan pers. comm.). Thus, we used the chl a signal as a surrogate for phytoplankton biomass and the ratio of optical backscattering at $700 \mathrm{~nm}$ to that of chl a concentration as a measure of the amount of non-living particulates, both organic and inorganic. 


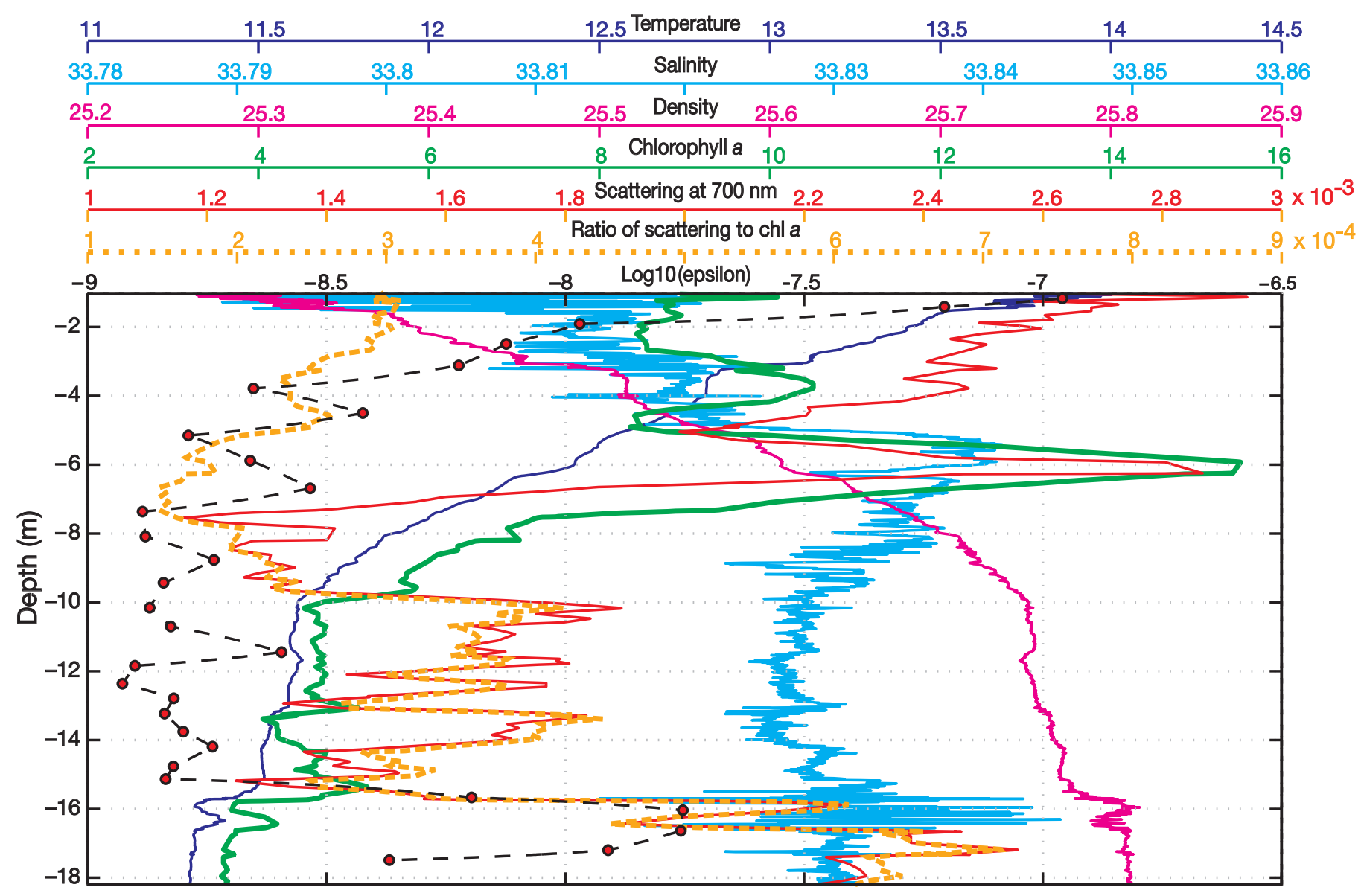

Fig. 3. Example set of profiles of physical and optical quantities estimated. Data were collected by the autonomous underwater vehicle T-REMUS at 20:50 h Pacific Daylight Time (PDT) on 17 July 2006, corresponding to the 10th profile of Leg 3. Color coding indicates: temperature $\left({ }^{\circ} \mathrm{C}\right)$, salinity $(\mathrm{psu})$, density $\left(\mathrm{kg} \mathrm{m}^{-3}\right)$, chlorophyll a $\left(\mu \mathrm{g} \mathrm{l}^{-1}\right)$, scattering at $\left.700 \mathrm{~nm}^{-1} \mathrm{~m}^{-1} \mathrm{sterad}^{-1}\right)$, the ratio of scattering at $700 \mathrm{~nm}$ to $\mathrm{chl} a\left(\mathrm{l} \mathrm{g}^{-1} \mathrm{~m}^{-1}\right.$ sterad $\left.^{-1}\right)$, and turbulent kinetic energy dissipation rate, $\varepsilon\left(\mathrm{W} \mathrm{kg}^{-1}\right)$

\section{RESULTS AND DISCUSSION}

\section{Example profiles}

In Fig. 3, we show one example of the vertical profiles of the various physical and optical parameters obtained by T-REMUS. Shown are data taken at 20:50 h PDT, 17 July 2006, corresponding to the 10th profile of Leg 3 . The figure shows, as color coded lines, profiles of temperature, salinity, density, chl a concentration, optical scattering at $\lambda=700 \mathrm{~nm}$, the ratio $\beta / \mathrm{c}(\beta$ : optical scattering at $700 \mathrm{~nm} ; C$ : chl a concentration), and TKE dissipation rate. The scattering at $\lambda=470 \mathrm{~nm}$ was found to be very similar to that at $\lambda=700 \mathrm{~nm}$ and, thus, is not shown. The CTD data showed a strong pycnocline with warmer, lower salinity water overlying denser, cooler, and saltier water. The largest stratification occurred at depths between $z=1$ and $10 \mathrm{~m}$. Note the step structure in density between $z=3$ and $7 \mathrm{~m}$. Density overturns occurred between 11.5 and $16.5 \mathrm{~m}$.
Below $16.5 \mathrm{~m}$, the density profile showed a bottom mixed layer of $5.5 \mathrm{~m}$ depth extent. For this latter estimate we have used the fact that the bottom was located $4 \mathrm{~m}$ below the deepest descent depth of the T-REMUS.

Because of the relatively small salinity change with depth, density and buoyancy frequency profiles were principally determined from temperature. However, salinity can be used as a fluid mass tracer. Accordingly, the sharp salinity gradient at $z=5.0 \mathrm{~m}$ was interpreted as a boundary between 2 different water mass types. Note that this demarcation is not as noticeable in the temperature profile (Fig. 3).

Dekshenieks et al. (2001) define the thin layer of a biological-based property, such as chl $a$, as occurring when its value exceeds 3 times that of its background value. If we use as a background value for chl $a$, its concentration in the bottom mixed layer, we get a background concentration value of $c_{\mathrm{bg}}=3.4 \mu \mathrm{g} \mathrm{l}^{-1}$, which then leads to the following criteria for a thin 
layer: $c>3 c_{\mathrm{bg}}=3 \times 3.4 \mu \mathrm{g} \mathrm{l}^{-1}=10.2 \mu \mathrm{g} \mathrm{l^{-1 }}$. This criteria was met for $c$ and $\beta$ between the depths of 5 and $7 \mathrm{~m}$ (Fig. 3). This occurred at the base of the largest change in salinity, indicating the demarcation between 2 different water masses. Note that the ratio of scattering at $700 \mathrm{~nm}$ to chl a concentration, $\beta / C$, did not show such an enhancement of its background value, which suggests that the chl a concentration was mainly composed of live phytoplankton. The profile of TKE dissipation rate, $\varepsilon$, showed the largest values, $\varepsilon>10^{-8} \mathrm{~W} \mathrm{~kg}^{-1}$, near the surface and in the bottom mixed layer. Because of the high $\beta / c$ ratio in the bottom mixed layer, the near bottom maxima of optical scattering at $\lambda=700 \mathrm{~nm}$ most likely resulted from non-living particles being swept up from the seafloor by the enhanced near bottom turbulence.

\section{Spatial structure}

Over an $8 \mathrm{~h}$ period, the AUV ran a continuous set of 12 parallel across-isobath tracks, with each sequential leg displaced $50 \mathrm{~m}$ to the southeast (see Fig. 1b). Each track contained 15 to 17 profiles similar to the ones shown in Fig. 3, resulting in contour plots of temperature, chl $a$, and eddy diffusivity as a function of acrossisobath distance and depth (Figs. 4 to 6). The location of the profiles used to make these contour plots (separated $150 \mathrm{~m}$ on average) is indicated by a sequential number on the top of each contour panel. The reversal of profile ordering between panels is a result of the reversal of the heading of the AUV. The individual profiles are located on average $150 \mathrm{~m}$ apart in the acrossisobath direction. The vertical black thick line is the across-shore location of the fixed observational Stn K1 (see Fig. 1b), located $250 \mathrm{~m}$ northwest of the T-REMUS tracks. The black jagged line above the grey area indicates the seafloor bottom, which deepens from 16 to $23 \mathrm{~m}$ going offshore. The start time of the sampling for each contour plot, as well as its leg number (1 to 12), is shown in the grey area below the seafloor bottom. Each leg of the contour plot represents data sampled sequentially on average 40 min apart, or, using a mean current of $0.1 \mathrm{~m} \mathrm{~s}^{-1}$, an upstream distance of $240 \mathrm{~m}$ apart. The abscissa of each contour plot is the offshore distance from the initial reference point at $36.94^{\circ} \mathrm{N}$, $121.91^{\circ} \mathrm{W}$, which is shown as the filled black circle in Fig. 1b. In each of these plots isotherms are spaced $0.2^{\circ} \mathrm{C}$ apart and shown as black lines.

In Fig. 4, we show contour plots of the temperature field obtained from the AUV-based FASTCAT CTD. Recall that temperature is the predominant contributor to density (see 'Materials and methods'). Note the occurrence of a warm surface layer moving offshore in Legs 1 to 12 . In Leg 4, this warm layer converged to form a very strong near-surface 'micro' front on the order of $300 \mathrm{~m}$ in horizontal extent centered at $x=-1300 \mathrm{~m}$. Leg 5 shows the occurrence of a discrete large downward displacement feature, which Goodman \& Wang (2008) have shown to be the leading isolated edge of an internal solitary wave. Using thermistor chain data from fixed Stn K1, Goodman \& Wang (2008) showed that there are 2 such isolated internal solitary waves which are then followed by a continuous internal wave train, arriving at the experimental site at Leg 8 and persisting until Leg 12. The white lines near the bottom of each contour plot represent temperature isotherms of $T=11,11.2$, and $11.4^{\circ} \mathrm{C}$; note their upslope propagation.

Fig. 5 shows chl a contour plots obtained from the T-REMUS BB2F fluorometer. The color bar scale to the right of each plot is in units of $\mu \mathrm{g} \mathrm{l}^{-1}$. As in the previous set of contour plots, temperature isotherms are shown as black lines. In Figs. $5 \& 6,2$ isotherms are highlighted by white lines: one at $T=12.8^{\circ} \mathrm{C}$, showing a demarcation between the upper warm water layer and the mid-water layer; and one at $T=11.2^{\circ} \mathrm{C}$, which separates the mid-water layer from that of the bottom mixed layer. Using our criteria of a thin layer, the $T=$ $12.8^{\circ} \mathrm{C}$ isotherm separates 2 individual thin layers of chl $a$, which we term the upper and mid-water thin layers. The upper thin layer occurred at the very beginning of the experiment at 19:00 h PDT, 17 July 2006, well before sunset (20:30 h PDT). It had a maximum chl a concentration of $60 \mu \mathrm{g} \mathrm{l}^{-1}$ (data not shown) and was strongest near shore. This upper thin layer weakened with time and eventually disappeared by Leg 7. Leg 4 shows what appears to be the beginning of the downward displacement of the upper thin layer chl a material inshore of Stn K1. By Leg 6 it had crossed the $T=$ $12.8^{\circ} \mathrm{C}$ isotherm into cooler, denser water.

The mid-water thin layer, located between isotherms $T=12.8^{\circ} \mathrm{C}$ and $T=11.2^{\circ} \mathrm{C}$ (Fig. 5), persisted over the entire $8 \mathrm{~h}$ experiment. It had a horizontal acrossisobath scale of at least $1.5 \mathrm{~km}$, which is probably an underestimate of its horizontal extent since it extended to the edge of the range of the T-REMUS measurements. Note the onshore stretching of the edge of this thin layer occurring along the $T=12.2^{\circ} \mathrm{C}$ isotherm and ranging between $x=-1000 \mathrm{~m}(\operatorname{Leg} 1)$ to $x=-500 \mathrm{~m}$ (Leg 4). In Leg 5, the isolated leading edge internal solitary wave which had propagated into the experimental site displaced this thin layer downward, and in Legs 6 to 10, parts of the thin layer appeared to break up into several smaller pieces. The internal solitary wave of Leg 5 also displaced downward the remnants of the upper thin layer, and in Legs 6 to 12 the chl $a$ concentration appeared to undergo enhanced dispersion. The mid-water thin layer did not penetrate through the $T=11.2^{\circ} \mathrm{C}$ isotherm, which seems to act as a barrier to material migration. 


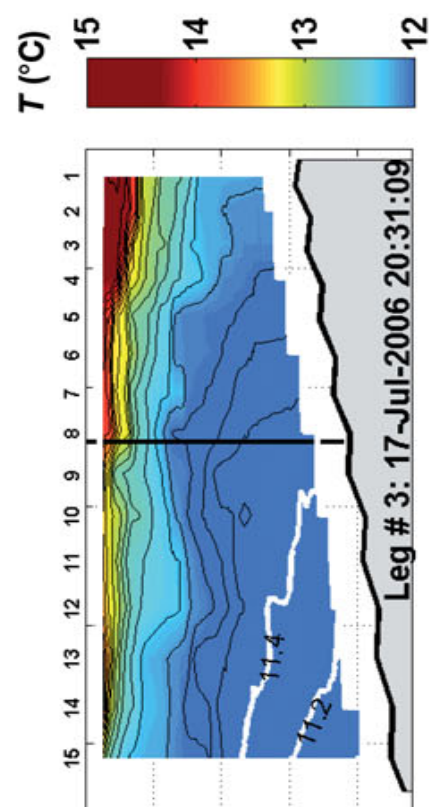

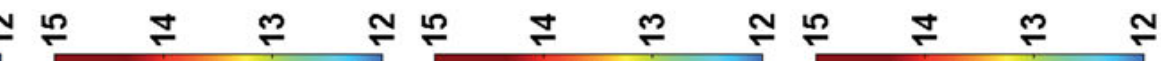
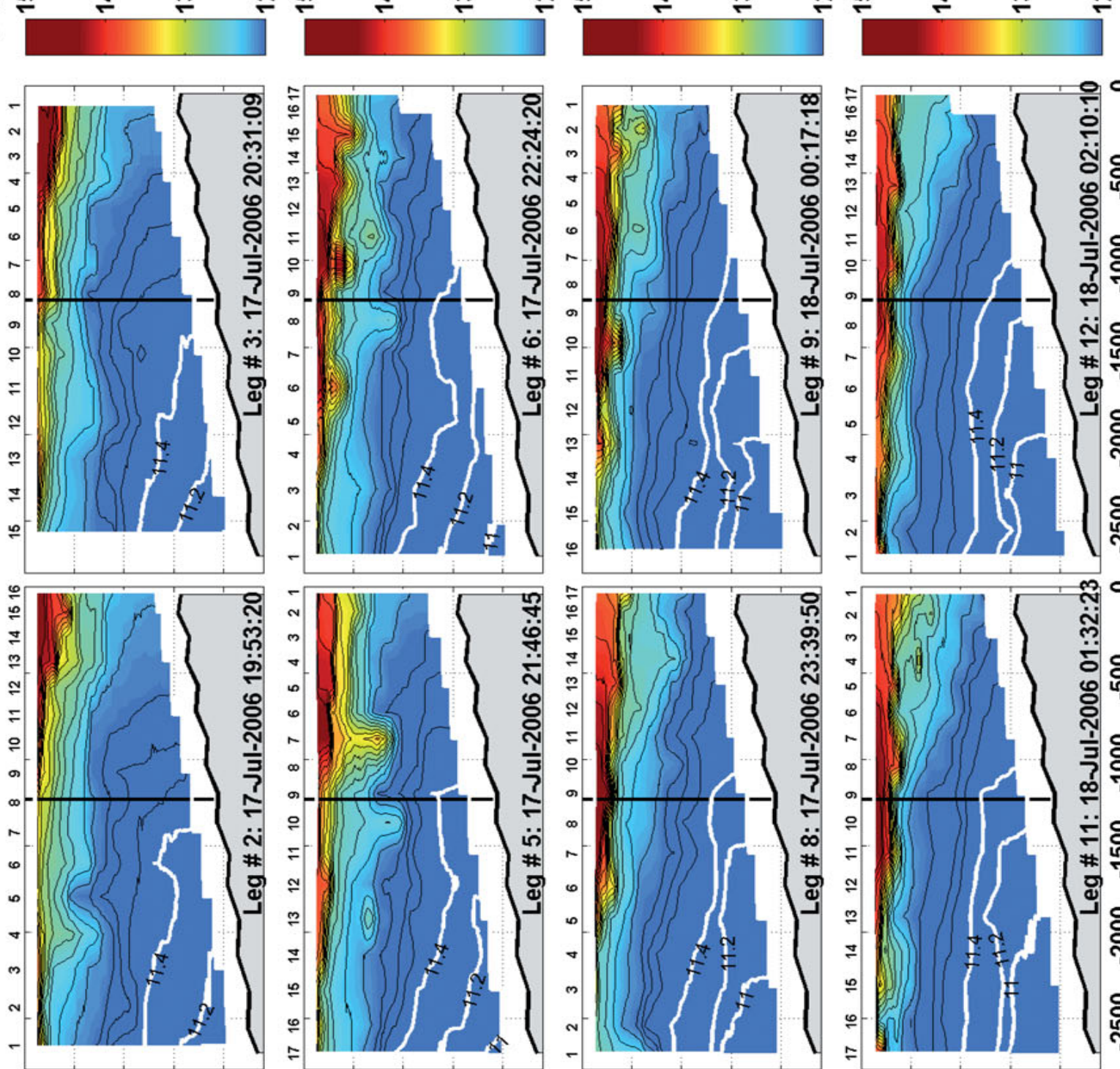

范

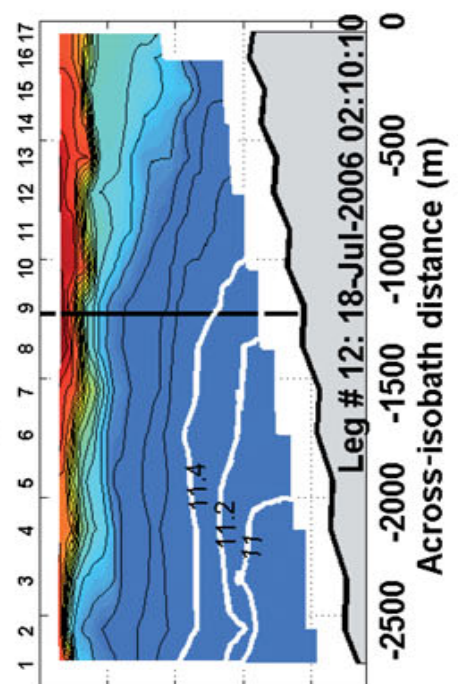

$\stackrel{0}{*}$
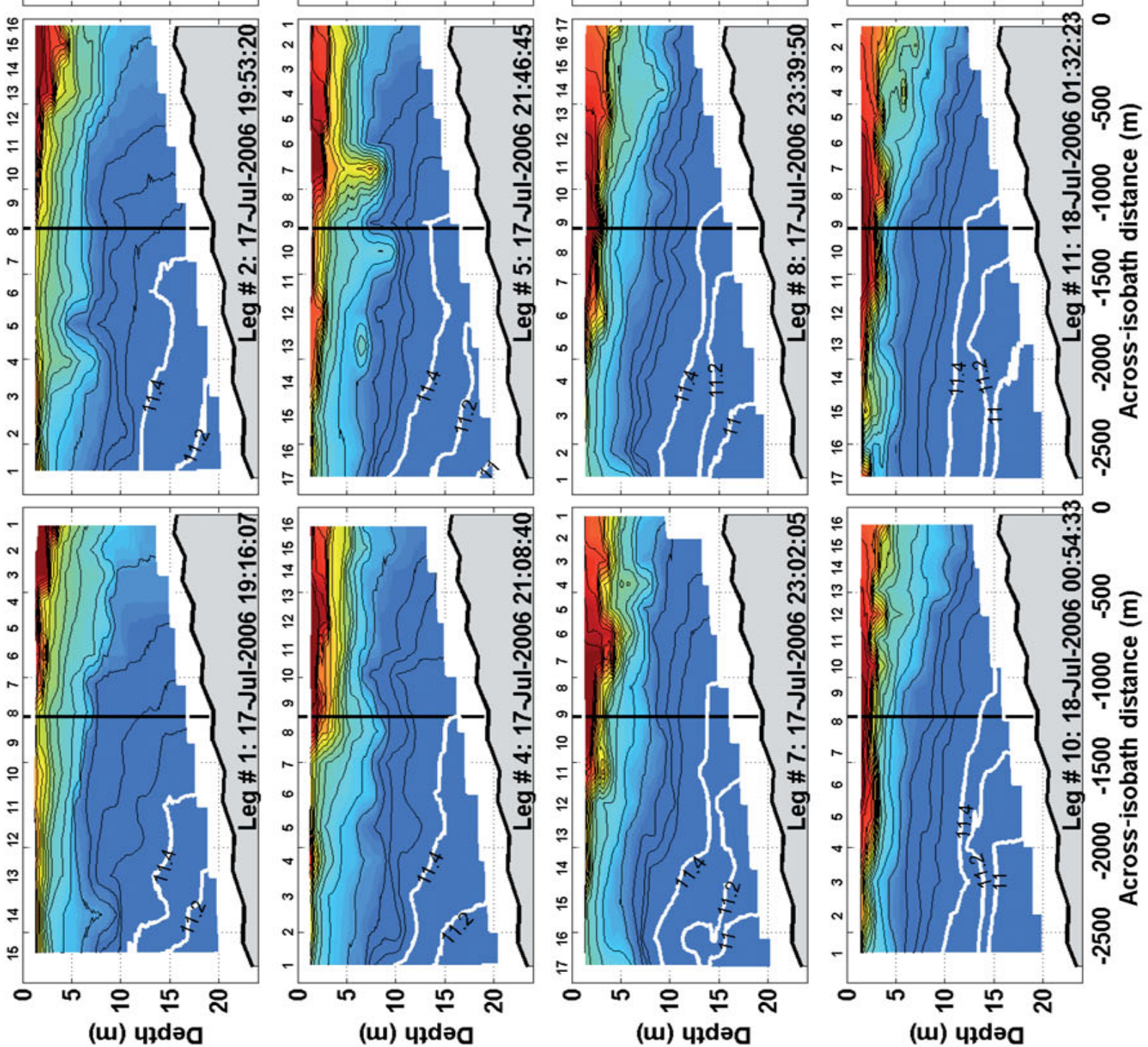

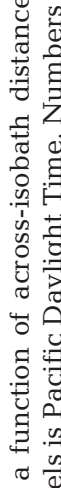

(2)

坖

U.

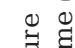

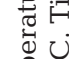

屯

ఫ్త

은

空

코 ป ?

我 

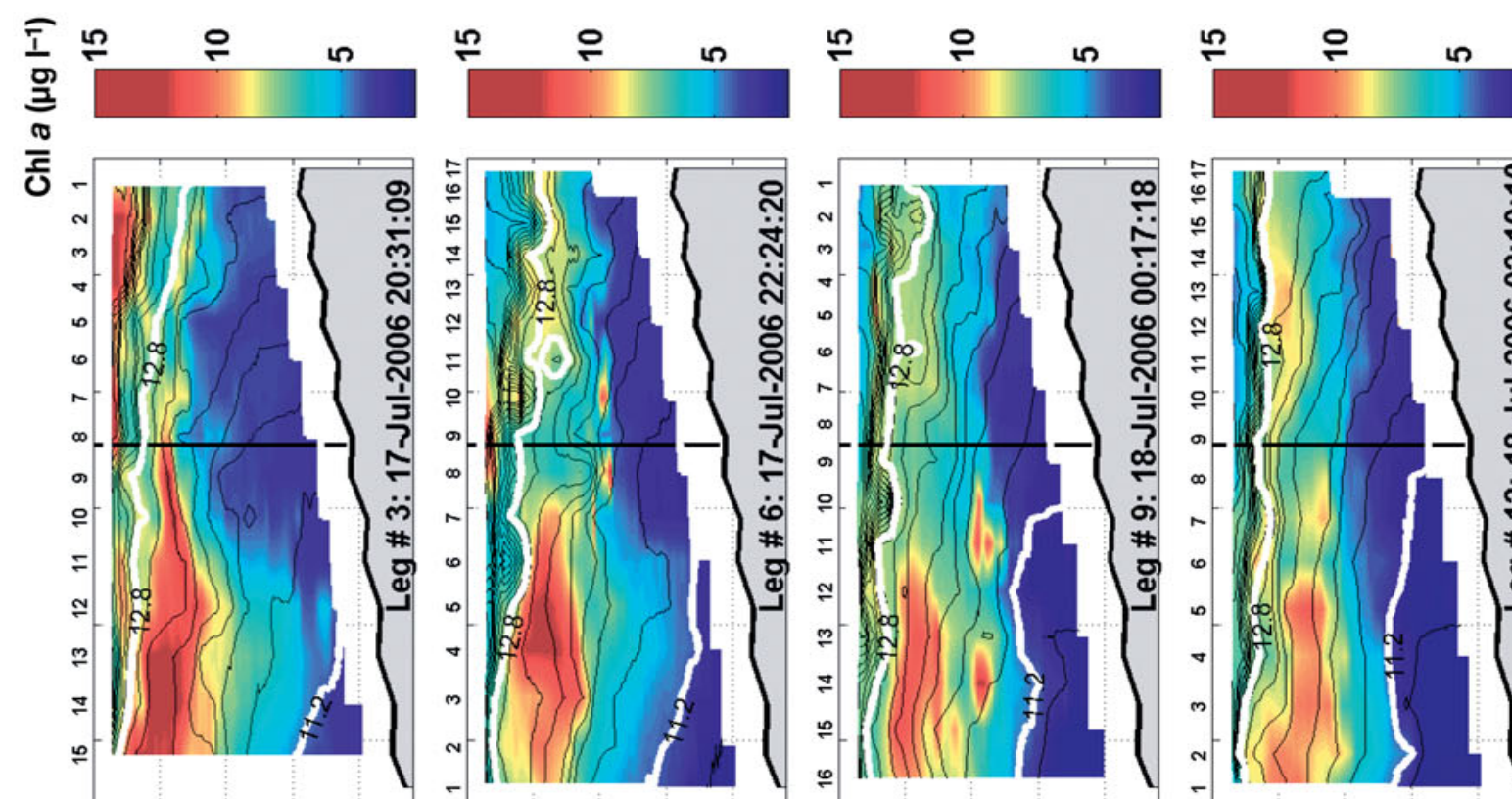

章
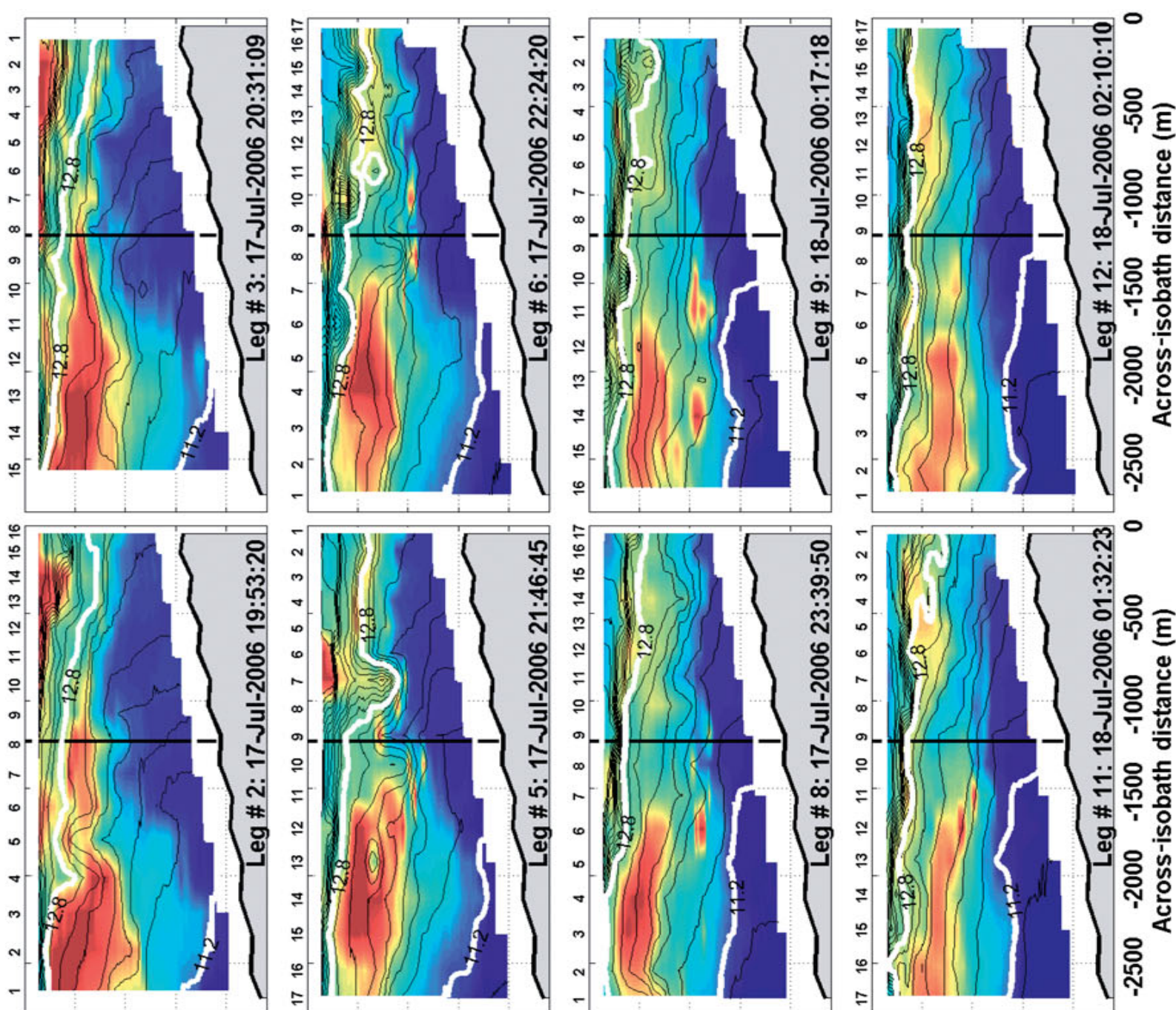

$\because$
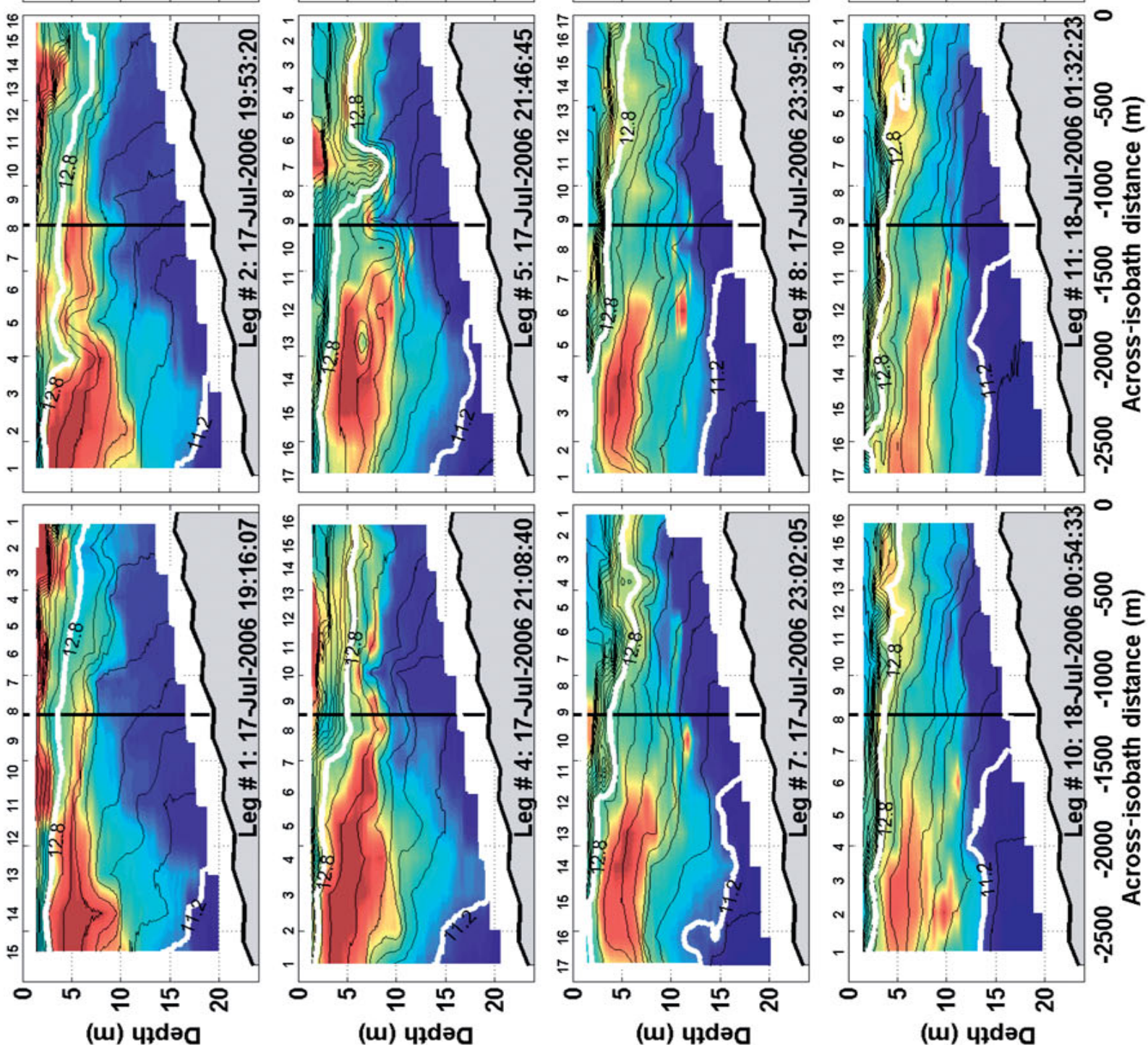

0

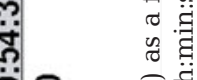
(u) पłdəa

(u) पłdә

(u) чұdә

(u) पұdәa

运 

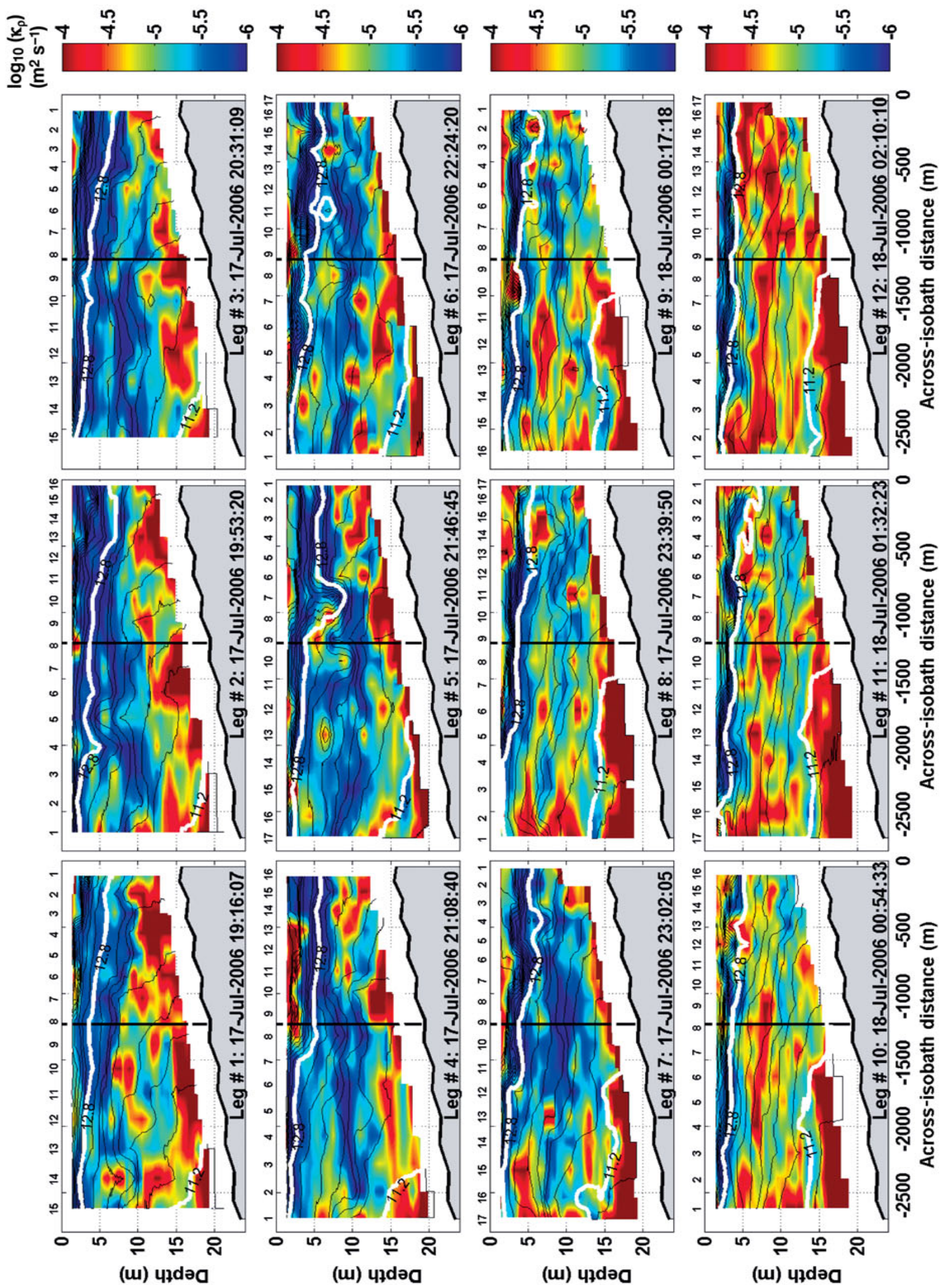
0
0
0
0
0
0
0
0
0
0
0
0
0
0
0
0
0
0
0
0
0
0
0
0
0
0
0
01
0
0
0
0
0
0

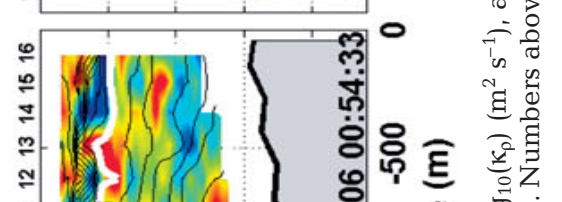

(u) ułdəa

(u) ułdəa

(u) पłdəa

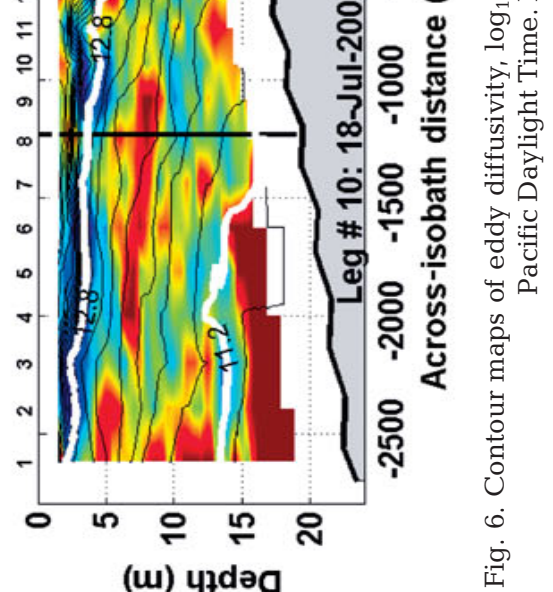


In Fig. 6, using Eq. (2) with measured values of $N$ and $\varepsilon$, we show eddy diffusivity contour plots. As indicated by Eq. (2), eddy diffusivity is linearly proportional to the buoyancy Reynolds number. Recall that strong turbulence corresponds to $\kappa_{\rho} \geq 4 \times 10^{-5} \mathrm{~m}^{2} \mathrm{~s}^{-1}$ (see 'Materials and methods'): in Fig. 6 we see strong turbulence at the base of the near-surface warm water intrusion, particularly within the 'micro' front region (Leg 4). Strong isolated patches of turbulence also occurred in the thermocline region (Legs 1 to 9). Note the patch of strong turbulence in Leg 5 in the lee of the leading edge isolated internal solitary wave. Strong, spatially continuous turbulence of $\kappa_{\rho} \geq 4 \times 10^{-5} \mathrm{~m}^{2} \mathrm{~s}^{-1}$ was present from Legs 8 to 12 and appeared to propagate from offshore to onshore. Goodman \& Wang (2008) argued that this turbulence is the result of vertical straining by the dispersive part of the internal wave train which had entered this region from offshore at the time of Leg 8.

In Figs. $7 \& 8$ we re-plot, using temperature in place of depth as the ordinate, contours of chl a concentration and the eddy diffusivity, respectively. Because of the small variation in salinity, temperature is a good surrogate for density. These types of plots minimize the distortion effect of internal waves on density surfaces and thus more clearly reveal cross-isopycnal transport than those presented in Figs. $5 \& 6$. We also show the spatial extent of the thin layers (black solid lines) defined by the criteria of Dekshenieks et al. (2001). The white dots in Figs. $7 \& 8$ are the center of mass of the mid-water (thermocline-based) thin layer.

Fig. 7 clearly identifies the 2 initially distinct thin layers, the one above and the one below the $T=12.8^{\circ} \mathrm{C}$ water mass boundary. The upper thin layer occurred for the most part shoreward of the across-isobath location of Stn K1. In Legs 1 to 3, the upper thin layer was strong, persistent, and distinct. However, beginning with Leg 2, some material in the upper thin layer at the acrossisobath location between $x=-1500 \mathrm{~m}$ and $x=-2000 \mathrm{~m}$ began to cross the $T=12.8^{\circ} \mathrm{C}$ water mass boundary. At almost the same across-isobath distance as in Leg 2, Leg 3 shows what appears to be a bulge in the upper surface of the lower thin layer. This bulge penetrates above the $T=12.8^{\circ} \mathrm{C}$ isotherm, and is most probably related to the feature seen at this across-isobath location in the upper layer of Leg 2. It was displaced downward and became contoured within the lower thin layer. Leg 4 shows remnants of this feature, as well as the beginning of a downward displacement of the shoreward part of the upper thin layer, a process which continued until the end of the experiment. At the end of the experiment, the upper thin layer has disappeared but a new thin layer feature at the same across-isobath location is present, but in the thermocline region between $x=-1200 \mathrm{~m}$ and $x=-300 \mathrm{~m}$. However, this suggests that the upper thin layer has migrated downward, because we were not following a specific feature we cannot be sure that it is composed of the same material as that of the upper thin layer observed at the beginning of the experiment. Legs 7 to 10 show what appears to be a strong dispersion of material in the upper thin layer with time.

The mid-water thin layer remained for the most part compact throughout the experiment, centered near the $T=12.3^{\circ} \mathrm{C}$ isotherm (Fig. 7). Legs 1 to 5 show it stretching and thinning, and Leg 6 shows a cessation of this effect with a retreat seaward accompanied by a weakening in concentration.

In Fig. 8 we show the contours of eddy diffusivity plotted in the same way as that of the chl a concentration shown in Fig. 7. We note, in the upper layer, islated regions of strong turbulence. The region of intense turbulence in Legs 6 to 10 corresponds to the same region where significant spreading of the upper thin layer began. Intense turbulence at the location of the mid-water thin layer began in Leg 7 and continued until the end of the experiment.

\section{Evolution of the chl a thin layers}

In order to quantify the evolution of the chl a material, we defined the average chl a concentration, $\overline{C_{1}}$ within each layer by:

$$
\bar{c}_{\gamma}=\frac{1}{A_{\gamma}} \int_{A_{\gamma}} \mathrm{d} A c_{\gamma}(x, z)=\frac{\int_{x_{1}}^{x_{2}} \int_{z_{T 1}}^{z_{T 2}} \mathrm{~d} x \mathrm{~d} z C_{\gamma}(x, z)}{\int_{x_{1}}^{x_{2}} \int_{z_{T 1}}^{z_{T 2}} \mathrm{~d} x \mathrm{~d} z}
$$

where each of the 3 isothermal layers are identified by the notation $\gamma=u, m, l$ corresponding to the: upper depth layer, $u, T>12.8^{\circ} \mathrm{C}$ i mid-depth (thermocline) layer, $m, 11.2^{\circ} \mathrm{C}<T<12.8^{\circ} \mathrm{C}$; and lower depth/bottom mixed layer, $l, T<11.2^{\circ} \mathrm{C}$. $T 1$ is the temperature at the upper boundary $z 1$ and $T 2$ is the temperature at the lower boundary $z 2$.

In Eq. (4), $A_{\gamma}$ is the cross sectional area of each of the 3 layers. Note that the upper layer contains the upper chl a thin layer, while the mid-depth layer contains the mid-depth, thermocline-based chl a thin layer. However, it should be noted that averages taken over the 3 layers include chl a material outside of the thin layers. If, within each layer, we assume that there was no growth or mortality, then we can use both background fluid and chl a mass flow conservation to examine the cross-isothermal (isopycnal) exchange of chl a.

From Figs. 5 \& 7 we note that the upper thin layer is mostly confined inshore of the K1 fixed station (solid black vertical line), while the mid-depth thin layer tends to be confined offshore of Stn K1. Thus, we further divided the layers into 2 regions: offshore and inshore of the location of the K1 line. We plotted the 


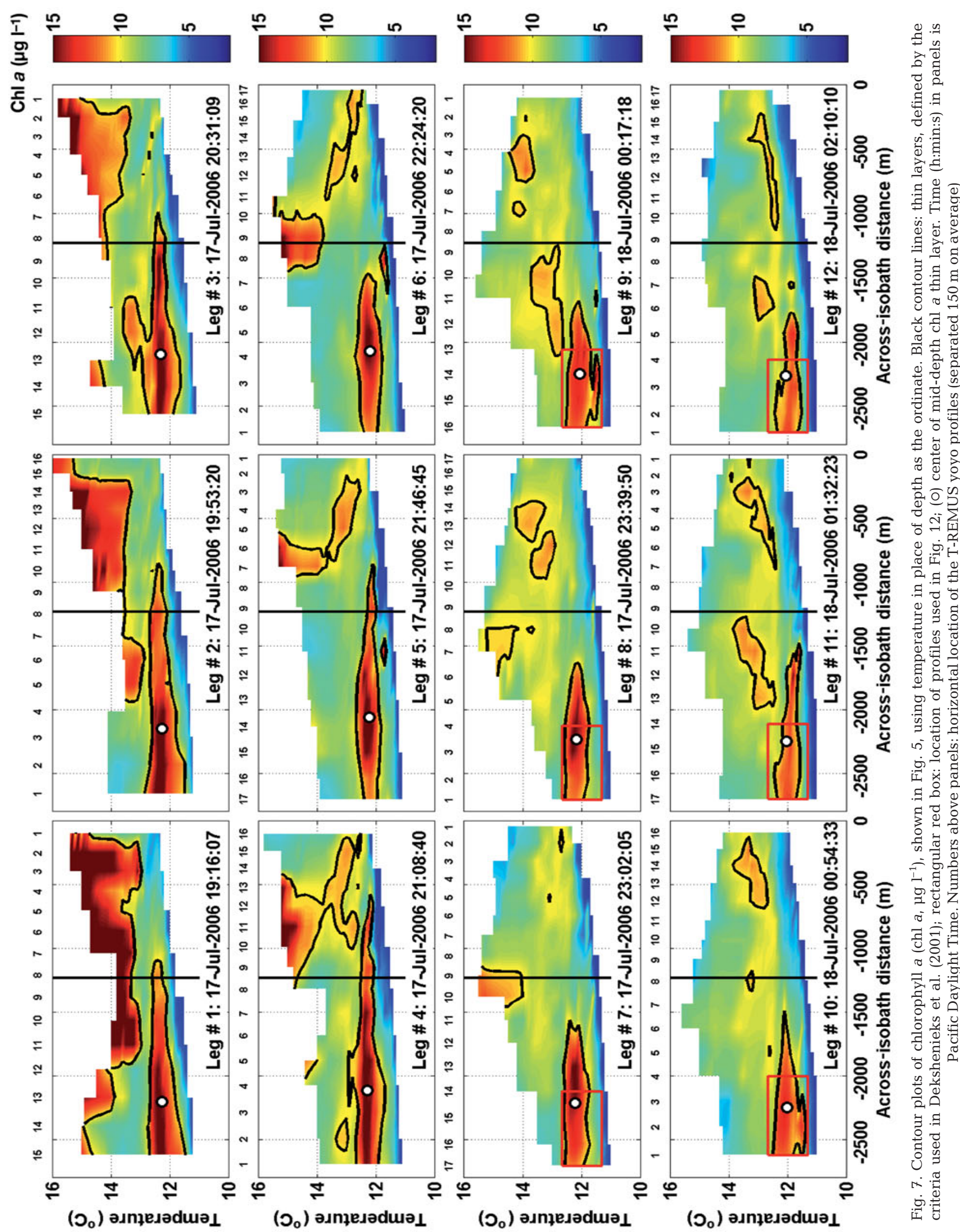




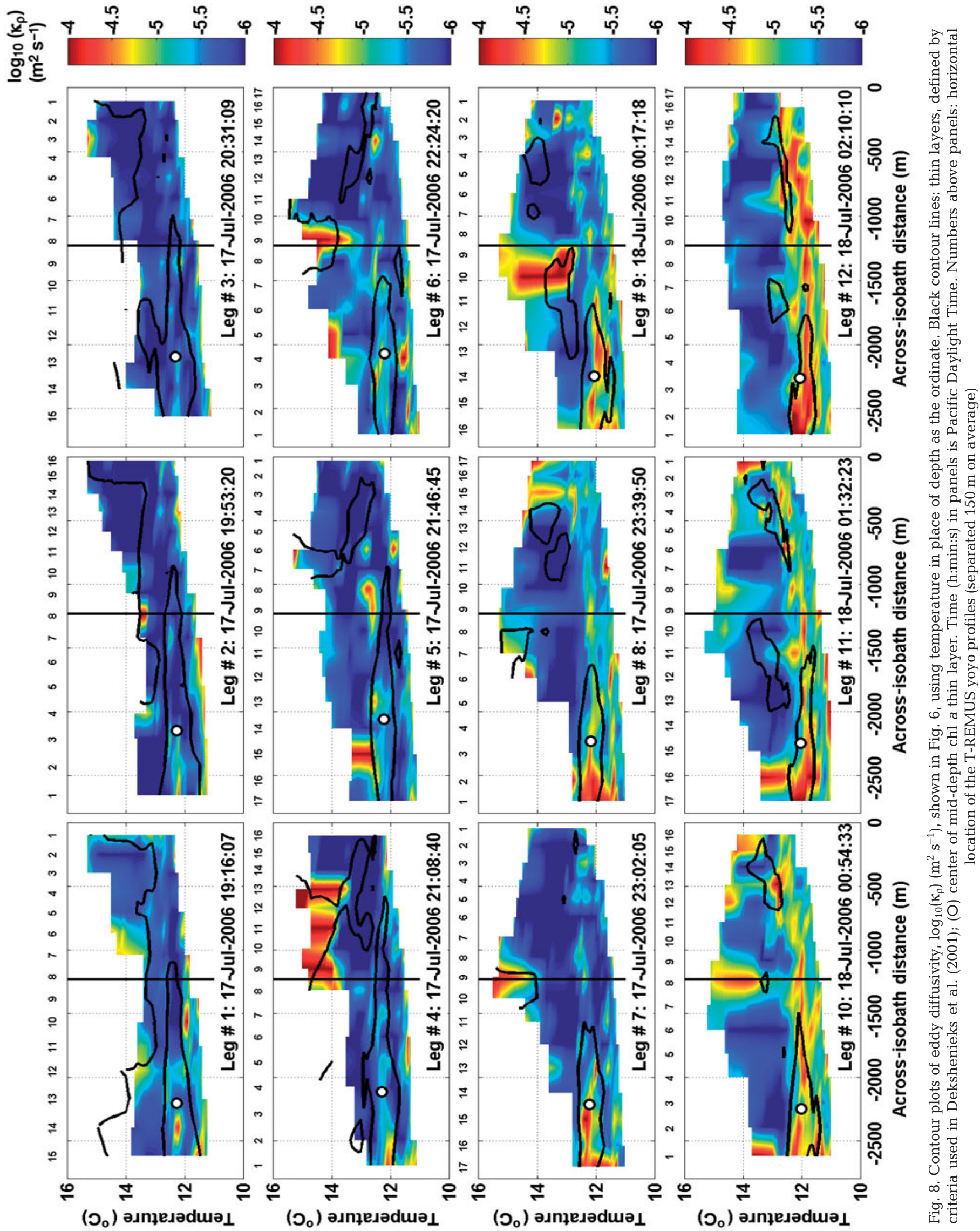



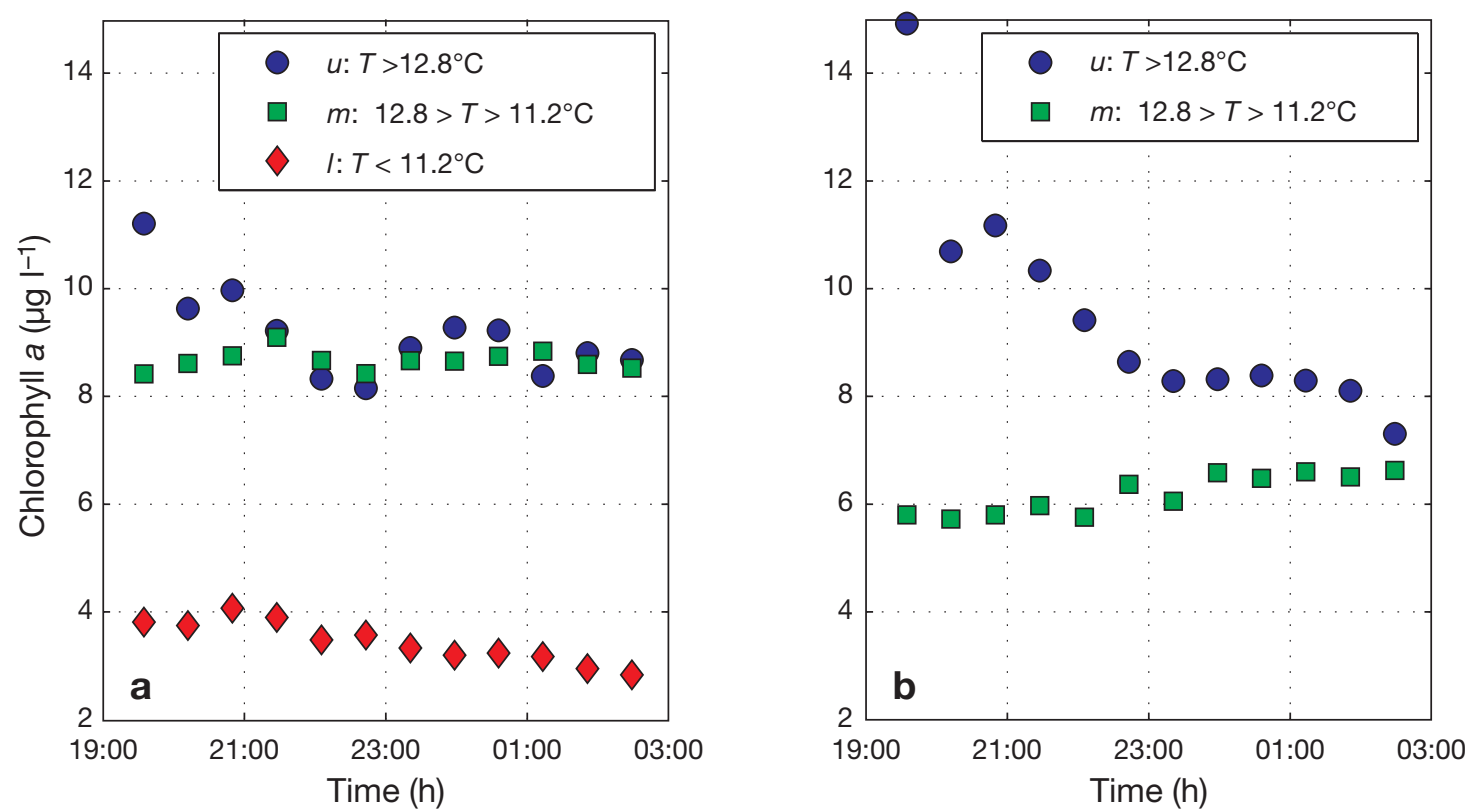

Fig. 9. Temporal evolution of the mean concentration of chlorophyll a (chl $a_{1} \bar{C}$ : (a) offshore and (b) inshore of Stn K1, 17-18 July 2006. Chlorophyll a concentration averaged in the upper layer $(u)$, temperature $(T)>12.8^{\circ} \mathrm{C} ;$ mid-depth layer $(m), 11.2^{\circ} \mathrm{C}<T<$ $12.8^{\circ} \mathrm{C}$; and lower layer $(1), T<11.2^{\circ} \mathrm{C}$. Time (h) is Pacific Daylight Time

temporal evolution of the concentration of the layered, averaged chl a concentration over the observational area offshore and inshore of Stn K1 in Fig. 9a \& b, respectively. In these figures, the upper layer chl $a$ concentration, $\bar{C}_{u}$, is shown as blue circles, and the mid-layer chl a concentration, $\bar{C}_{m}$, as green squares. In Fig. 9a we also plot lower layer chl a concentration, $\bar{c}_{l}$, as red diamonds. Since the lower layer occurs at a temperature below $11.2^{\circ} \mathrm{C}$, its associated chl a concentration does not occur shoreward of Stn K1. Each point in Fig. 9 is the average of 8 or 9 across-isobath profiles, resulting in an error variance of less than $15 \%$.

There was a significant decrease in the first $2 \mathrm{~h}$ of the upper layer offshore chl a concentration, $\bar{c}_{u}$, beyond which time it asymptotes to $\bar{c}_{u} \approx 8.8 \mu \mathrm{g}^{-1}$ (Fig. 9a). The offshore mid layer shows a small increase in $\bar{C}_{m}$ during the first $2 \mathrm{~h}$ and then, just as in the upper layer, asymptotes to the concentration level of $\bar{c}_{m} \approx 8.8 \mu \mathrm{g} \mathrm{l^{-1 }}$. These results, along with the character of the features of the thin layer shown evolving in Fig. 7, suggest that for the most part the offshore mid-depth layer is isolated from the upper and lower layers. It is interesting to note that the bottom mixed layer underwent a monotonic decrease of $\bar{c}_{l}$ over the entire extent of the experiment (Fig. 9a). As previously discussed (see Fig. 4), the isotherm which is the upper boundary of the bottom mixed layer moved upslope with time. The bottom water contained within this boundary, originating offshore of the experimental site, was presumably of lower chl a concentration. The upward advection and mixing of this bottom water of lower chl a concentra- tion would then result in dilution and give the monotonic decrease of $\bar{c}_{l}$, shown in Fig. 9a.

In Fig. 9b, the concentration of the upper layer inshore of Stn K1 shows a significant decrease in chl a from a maximum of $\bar{C}_{u} \sim 15 \mu \mathrm{g} \mathrm{l}^{-1}$ down to $\bar{C}_{u} \sim 8.3 \mu \mathrm{g} \mathrm{l}^{-1}$ over the first $4 \mathrm{~h}$, and then remained constant until near the very end of the experiment, where we saw a sudden decrease to $\bar{C}_{u} \sim 7.3 \mu \mathrm{g} \mathrm{l^{-1 }}$ at the very last observed time. Chl a occurring in the mid layer in shore of K1 showed a monotonic increase in concentration from $\bar{c}_{m} \sim 5.9 \mu \mathrm{g} \mathrm{l}^{-1}$ to $\bar{C}_{m} \sim 6.7 \mu \mathrm{g} \mathrm{l^{-1 }}$.

Since we do not know the depth extent of the upper thin layer, we do not have data over the complete area and thus cannot perform a chl a mass flux balance between the inshore 2 layers. However, the pattern of evolution shown in Fig. 7 does suggest downward migration of phytoplankton in the offshore upper thin layer into the offshore mid-depth layer (note that this began around sunset).

Let us now examine in more detail the evolution of the mid-depth chl a thin layer, which for the most part is located offshore of the K1 line. In Fig. 10, we show the temporal evolution of the depth of center of mass of this thin layer taken relative to its initial depth, using the stretched vertical coordinate $\tilde{z}$. The stretched vertical coordinate represents the across-isobath averaged isotherm, $T$, and is given by $\tilde{Z}(T)=1 / L \int \mathrm{d} x z(T, x)$, where $L$ is the across-isobath length of integration for each leg sample. Expressing the center of mass of the chl a thin layer in this vertical coordinate system minimizes the distorting effect of internal waves (Goodman \& 


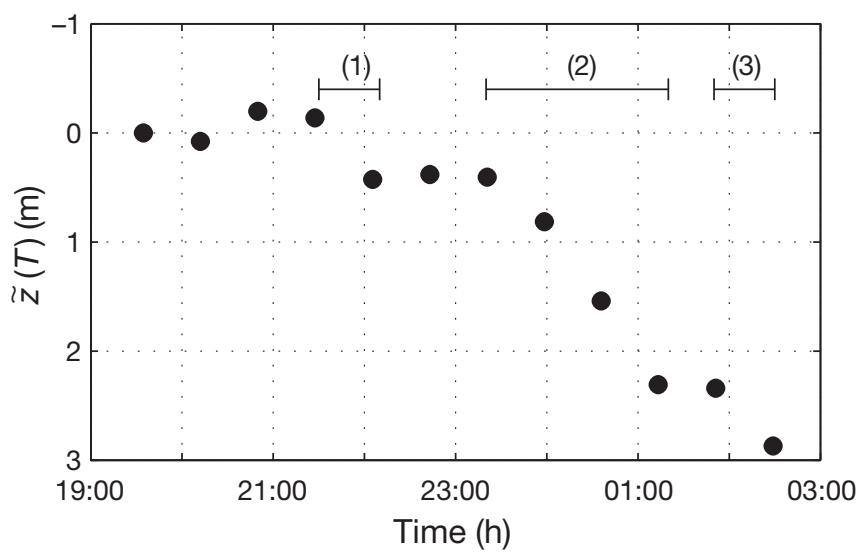

Fig. 10. Change in depth of the center of mass of the middepth chlorophyll a thin layer. A 'stretched' vertical coordinate $(\widetilde{z})$ based on mean isotherm depth is used. $T$ : temperature. Changes in depth are noted during 3 time periods from 17 to 18 July 2006: (1) $21: 30$ to $22: 10 h_{\text {; }}$ (2) $23: 20$ to $01: 20 h_{\text {; }}$ and (3) 01:50 to 02:30 h Pacific Daylight Time

Wang 2008). Recall that the mid-depth chl a thin layer vertical center position in local depth coordinates is indicated by the white circle in Figs. $7,8 \& 11$.

Fig. 10 shows initially constant values of the depth of the center of mass until 21:30 h PDT. Changes in depth are noted during 3 periods: (1) from 21:30 to $22: 10 \mathrm{~h}$; (2) from 23:20 to 01:20 $h_{\text {; }}$ and (3) from 01:50 to $02: 30 \mathrm{~h}$ PDT. The most significant change occurred during Period 2, when the center moved downward $2.1 \mathrm{~m}$. This corresponds to a downward speed of $w=2.1 \mathrm{~m} /$ $(2 \times 3600 \mathrm{~s}) \approx 290 \mu \mathrm{m} \mathrm{s}^{-1}$. Period 1 occurred at the time of the significant downward displacements associated with the isolated internal solitary wave (see Fig. 5, Leg 5). Period 3 occurred at the end of the experiment, when strong turbulence was observed in the thermocline throughout the experimental area.

Using a variety of observational data from planktonic organisms of all sizes, Okubo (1987) has suggested the empirical relationship:

$$
\operatorname{Re}=w d / v=A d^{1.86}
$$

between the characteristic organism size, $d$, and its vertical velocity, $w$, where Re is the Reynolds number, $v$ the kinematic molecular viscosity, and $A=1.4 \times 10^{6}$, a numerical constant with units of $\mathrm{m}^{-1.86}$. It is straightforward to show that Eq. (5) is a modification of a Stokes drag law. Using $v=10^{-6} \mathrm{~m}^{2} \mathrm{~s}^{-1}$ and the observed value of $w=290 \mu \mathrm{m} \mathrm{s}^{-1}$ yields $d=52 \mu \mathrm{m}$, a value within the range of individual phytoplankton found at the LOCO site. A velocity estimated from the downward motion of the center of the mid layer chl a concentration reflects the average movement of a whole community, presumably of varying sizes, shapes, and orientations relative to the vertical. Note that from Eq. (5), variation in the terminal velocity $w$ is proportional to $d^{0.86}$.
Fig. 11 shows contour maps of the turbulent velocity scale, $w^{\prime}$, given by Eq. (3), plotted on a log-scale versus across-isobath range and temperature. Until the appearance of the internal solitary wave train in Leg 5, the turbulent velocity within the thin layer, apart from small, isolated intense patches, was typically small, on the order of $w^{\prime}=300 \mu \mathrm{m} \mathrm{s}^{-1}$. However, starting with Leg 5 and then significantly increasing by Leg 7, we see turbulent velocity within the thin layer increasing to values in excess of $W^{\prime}=3 \mathrm{~mm} \mathrm{~s}^{-1}$, the maximum value of the color bar scale to the right. Initially, at Leg 7 the strong turbulence characterized by a turbulent velocity $w^{\prime}>3 \mathrm{~mm} \mathrm{~s}^{-1}$ was confined to about half of the thin layer area. But, by the end of the experiment, virtually the entire thin layer area was filled with turbulence with velocities in excess of $w^{\prime}=3 \mathrm{~mm} \mathrm{~s}^{-1}$. In progressing from Legs 7 to 12, the thin layer appeared to coalesce into the same region as the intense turbulence, with the latter appearing to have thinned and strengthened between Legs 7 and 12. It was during this period that the most significant deepening of the center of the mid-depth thin layer occurred (Fig. 10). The phytoplankton thus appears to settle into and become trapped in the high turbulent region. It should be noted that the bottom of the thin layer/turbulent region in Leg 12 of Fig. 11 is characterized by a large density (temperature) gradient (also indicated in Fig. 6, Leg 12). This large change in density would be expected to inhibit phytoplankton settling.

\section{Vertical dispersion and contraction}

To examine in more detail the nature of the evolution of the thermocline-based thin layer, we plotted averaged vertical profiles of chl $a$ in the thin layer, $\tilde{c}(\tilde{z}, t)$, where $\widetilde{\mathrm{c}}$ is the averaged chl a vertical profiles in the stretched vertical coordinate $\widetilde{\mathrm{z}}$, and $t$ is time (Fig. 12). These profiles were obtained by averaging the 4 most seaward T-REMUS profiles of 2 consecutive legs. For the depth coordinate we used the stretched vertical coordinate $\tilde{z}$. The rectangular red box of Fig. 7 shows the location of the profiles used. In Fig. 12 the blue line is obtained from averages over Legs 7 and 8; the green line, over Legs 9 and 10; and the red line, over Legs 11 and 12. These profiles clearly show the deepening effect, observed in Fig. 10, for the thin layer mean vertical position. Between Legs 7 and 8 and Legs 9 and 10 there is a significant spreading of the profile, presumably due to the spreading of the turbulent field, as indicated between Legs 7 and 8 and 9 and 10 of Figs. 8 and 11. If we use the T-REMUS-derived observed eddy diffusivity value of $\kappa_{\rho} \approx 5 \times 10^{-5} \mathrm{~m}^{2} \mathrm{~s}^{-1}$ during this time period, and the change of time between the set of profiles $(\Delta t=80 \mathrm{~min})$, we would find that the root mean 


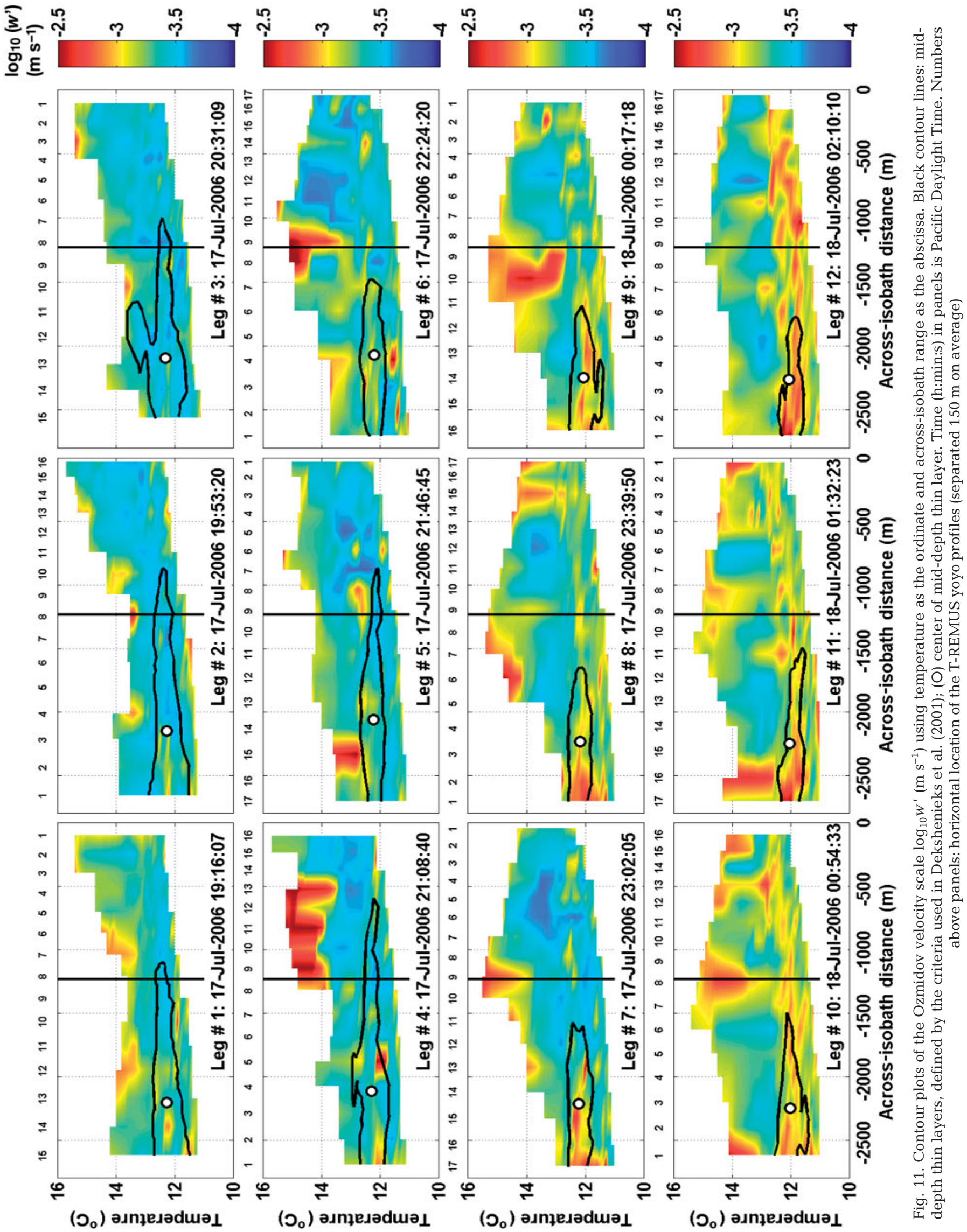




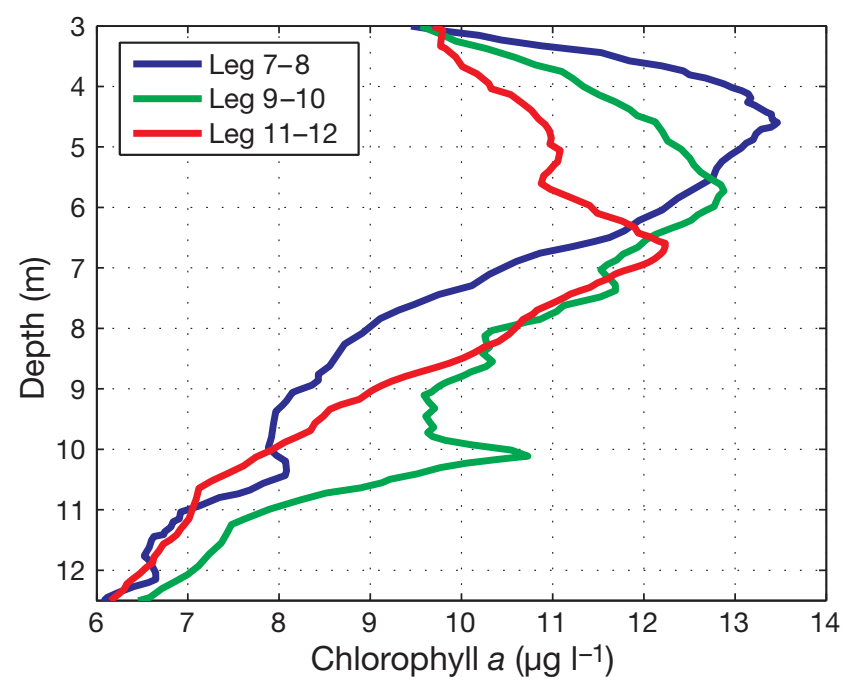

Fig. 12. Vertical profiles of the mid-depth chlorophyll $a$ thin layer, averaged over the area of 2 consecutive red boxes shown in Fig 7. The 'stretched' vertical coordinate is used for depth

square change in the variance of these profiles is given by $\Delta \sigma_{z}=\sqrt{2 \kappa_{\rho} \Delta t} \approx 0.7 \mathrm{~m}$. This estimated value is about the magnitude of the change in spread (about their respective maximum values) between the green and blue curves indicated in Fig. 12. This supports the idea that the green curve evolves from the blue curve by a combination of sinking and turbulent diffusion. Again we note that this is a period of time of increasing turbulence in the mid-layer.

Between Legs 9 and 10 and 11 and 12 there is the opposite effect on the vertical structure of the chl $a$ profile, namely a vertical contraction. Legs 9 to 12 of the contour maps in Figs. $7 \& 11$ also clearly show the vertical contraction process. Since the averaged terminal velocities of the phytoplankton in the thin layer estimated previously were much smaller than the turbulence velocity $w^{\prime}$ (see Fig. 11), the thin layer material should follow fluid parcels as a Lagrangian tracer and contract concurrently with that of the turbulent layer.

This contraction is most probably the result of the collapse of the turbulent field in the thermocline by the surrounding stratification of the fluid. The turbulence collapse in a stratified fluid can be explained as follows. Initially, the size (height) of turbulent eddies in the stratified fluid grow in the same way as those in an unstratified fluid (Schooley \& Stewart 1963). Turbulent mixing causes an increase in the potential energy in the mean background fluid. This occurs because the turbulent mixing results in turbulent eddies no larger than the size of the buoyancy or Ozmidov scale. Thus, the turbulent eddies approach a limiting vertical length scale where no further increase in their vertical extent can occur (Tennekes \& Lumley 1972). The height of eddies will then decrease with time (Lin \& Pao 1979, Lange 1982) as the turbulence weakens and the buoyancy becomes increasingly important, decreasing the Ozmidov scale. This effect has been clearly documented in the classical laboratory studies of Schooley \& Stewart (1963), Stockhausen et al. (1966), Merritt (1972), Lin \& Pao (1979), Lange (1982), and most recently by Chernykh et al. (2005). The collapse of turbulence can also be seen in the evolution of a Kelvin-Helmholtz instability such as is shown in the pioneering in situ dye studies of Woods (1968).

\section{CONCLUSIONS}

A field experiment was undertaken to study the physical mechanisms involved in the evolution of thin phytoplankton layers. The experiment took place in the northeast bight of Monterey Bay on the evening of 17-18 July 2006 and was part of the ONR sponsored LOCO experiment. The observational approach was to deploy the AUV T-REMUS, which contains a variety of fine- and micro-scale optical and physical sensors. Usage of the T-REMUS vehicle allowed simultaneous and collocated measurements of the chl a field as well as the local density, shear, and turbulence fields.

T-REMUS was operated at a $5^{\circ}$ yoyo mode, moving at a constant speed of $1.2 \mathrm{~m} \mathrm{~s}^{-1}$. Sampling occurred over depths from $1 \mathrm{~m}$ below the surface to $4 \mathrm{~m}$ above the bottom. From the response and averaging times of the sensors employed and the spatial structure of the yoyo AUV sampling, turbulence-derived quantities such as dissipation rate, eddy diffusivity, and turbulent velocity scale could be estimated with a vertical resolution of $0.5 \mathrm{~m}$ and an average horizontal resolution of $150 \mathrm{~m}$. Using the WET Labs BB2F triple puck sensor system, chl a data was obtained with a vertical resolution of $0.1 \mathrm{~m}$ and an average horizontal resolution of $150 \mathrm{~m}$. The vehicle was run for $8 \mathrm{~h}$ starting at 19:00 h PDT on 17 July 2008 and performed 12 across-isobath tracks parallel to the K-line. Each leg was approximately $2.5 \mathrm{~km}$ in length.

Two chl a thin layers were observed during the AUV experiment, one near the surface and one at middepth. The near-surface thin layer was observed at the beginning of the experiment, right before sunset. It then subsequently moved downward into the thermocline. The mid-depth thermocline-based thin layer remained intact prior to sunset and then was characterized by a decrease in its spatially integrated chl a content. A 'stretched' vertical coordinate based on the isotherm vertical displacement was used in this calculation to minimize the distorting effect of internal waves. At the mid-point of the experiment, approxi- 
mately 23:00 h PDT on 17 July 2006, an internal wave train moved into the area (Goodman \& Wang 2008). This wave train, through vertical straining, produced strong turbulence, which was characterized by high buoyancy Reynolds number, $\mathrm{Re}_{\mathrm{b}}>200$, dissipation rates, $\varepsilon \geq 10^{-7} \mathrm{~W} \mathrm{~kg}^{-1}$, eddy diffusivities, $\kappa_{\rho}>4 \times 10^{-5} \mathrm{~m}^{2}$ $\mathrm{s}^{-1}$, and turbulent velocities, $w^{\prime}>3 \mathrm{~mm} \mathrm{~s}^{-1}$. Estimates of the settling velocity for the thermocline based chl $a$ thin layer yielded $w \leq 0.3 \mathrm{~mm} \mathrm{~s}^{-1}$. We thus have concluded that the phytoplankton in this thin layer being mainly diatoms, obeying a modified Stokes drag law of the form Eq. (5), would behave as a passive Lagrangian tracer in this turbulent flow regime.

From the time of arrival of the internal wave train at $t=23: 00 \mathrm{~h} \mathrm{PDT}, 17$ July 2006, until the end of the experiment at 03:00 $\mathrm{h}$ PDT the following morning, the mid-depth thin layer became increasing filled with strong turbulence, characterized by $W^{\prime} \gg w$. With time, the turbulent layer contracted (thinned) in vertical extent. The phytoplankton thin layer first started to sink into the turbulent thin layer. Then, being caught up in the turbulent layer, was dispersed throughout it, and as the turbulent field contracted vertically the chl a material contracted with it. During this time period, the offshore mid-depth layer total integrated chl a content remained approximately constant.

For this particular case of a thin layer evolving in the thermocline with the turbulence residing on a very steep density gradient, over the short time scale observed in this experiment (h), the phytoplankton thin layer acted as a passive Lagrangian tracer and tended to follow the same spatial evolution pattern as that of the turbulence. In contrast to previous studies where thin layers were hypothesized to be only present in locations where the turbulence was weak (Dekshenieks et al. 2001, Alldredge et al. 2002, McManus et al. 2003, 2005), in the present study we find the opposite case, namely that thin layers can occur in strong turbulent layers. This occurs because the turbulence itself is also constrained into a thin layer. Although turbulence disperses the phytoplankton thin layer, it collapses due to density stratification and limits the diffusion of the phytoplankton layer. Thus, the phytoplankton layer appears to be trapped in the collapsed turbulent layer.

Acknowledgements. We gladly acknowledge and appreciate the support of the US Office of Naval Research and J. Eckman. We also thank J. Sullivan and P. Donaghay for the valuable conversations.

\section{LITERATURE CITED}

Alldredge AL, Cowles TJ, MacIntyre S, Rines JEB and others (2002) Occurrence and mechanisms of formation of a dramatic thin layer of marine snow in a shallow Pacific fjord. Mar Ecol Prog Ser 233:1-12
Chernykh GG, Fomina AV, Moshkin NP (2005) Passive scalar dynamics in turbulent wakes of bodies moving in a linearly stratified medium. Russ J Numer Anal Math Model 20:403-423

> Dekshenieks MM, Donaghay PL, Sullivan JM, Rines JEB, Osborn TR, Twardowski MS (2001) Temporal and spatial occurrence of thin phytoplankton layers in relation to physical processes. Mar Ecol Prog Ser 223:61-71

Dillon TM, Caldwell DR (1980) The Batchelor spectrum and dissipation in the upper ocean. J Geophys Res 85:1910-1916

Donaghay PL (2004) Profiling systems for understanding the dynamics and impacts of thin layers of harmful algae in stratified coastal waters. Proceedings of the 4th Irish Marine Biotoxin Science Workshop. Marine Institute, Galway, p 44-53

Donaghay PL, Osborn TR (1997) Toward a theory of biological-physical control of harmful algal bloom dynamics and impacts. Limnol Oceanogr 42:1283-1296

Donaghay PL, Rimes HM, Sieburth JM (1992) Simultaneous sampling of fine scale biological, chemical and physical structure in stratified waters. Ergebn Limnol 36:97-108

Goodman L, Wang Z (2008) Turbulence observations in the Northern Bight of Monterey Bay from a small AUV. J Mar Syst (in press)

Holliday DV, Pieper RE, Greenlaw CF, Dawson JK (1998) Acoustical sensing of small scale vertical structures in zooplankton assemblages. Oceanography 11:18-23

Holliday DV, Donaghay PL, Greenlaw CF, McGehee DE, McManus MM, Sullivan JM, Miksis JL (2003) Advances in defining fine- and micro-scale pattern in marine plankton. Aquat Living Resour 16:131-136

> Lange R (1982) An experimental study of turbulence behind towed biplanar grids in a salt-stratified fluid. J Phys Oceanogr 12:1506-1513

Lazier JR, Mann KH (1989) Turbulence and the diffusive layers around small organisms. Deep-Sea Res 36:1721-1733

Lin JT, Pao YH (1979) Wakes in stratified fluids. Annu Rev Fluid Mech 11:317-338

> Lueck RG, Wolk F, Yamazaki H (2002) Oceeanic velocity microstrcutre measurments in the 20th century. J Oceanogr 58:153-173

Luketina DA, Imberger J (2001) Determining turbulent kinetic energy dissipation from Batchelor curve fitting. J Atmos Ocean Technol 18:100-113

> MacDonald DG, Goodman L, Hetland RD (2007) Turbulent dissipation in a near field river plume: a comparison of control volume and microstructure observations with a numerical model. J Geophys Res 112:C07026, doi:10.1029/ 2006JC004075

MacIntyre S, Alldredge AL, Gotschalk CC (1995) Accumulation of marine snow at density discontinuities in the water column. Limnol Oceanogr 40:449-468

McManus MA, Alldredge AL, Barnard A, Boss E and others (2003) Changes in characteristics, distribution and persistence of thin layers over a 48 hour period. Mar Ecol Prog Ser 261:1-19

> McManus MA, Cheriton OM, Drake PJ, Holliday DV, Storlazzi CD, Donaghay PL, Greenlaw CF (2005) The effects of physical processes on the structure and transport of thin zooplankton layers in the coastal ocean. Mar Ecol Prog Ser 301:199-215

Merritt GE (1972) Wake laboratory experiment. CAL NOSC5047-A-2, Cornell Aeronaut Lab, Buffalo, NY

> Nielsen TG, Kiørboe T, Bjørnsen PK (1990) Effect of a Chrysochromulina polylepis subsurface bloom on the planktonic community. Mar Ecol Prog Ser 62:21-35

Okubo A (1987) Fantastic voyage into the deep: marine 
biofluid mechanics. In: Teromoto, E, Yamaguti, M (eds) Mathematical topics in population biology, morphogenesis and neurosciences. Springer-Verlag, New York, p 32-47

Osborn TR (1980) Estimates of the local rate of vertical diffusion from dissipation measurements. J Phys Oceanogr 10: 83-89

Osborn TR (1998) Finestructure, microstructure and thin layers. Oceanography 11:36-43

Rines JEB, Donaghay PL, Dekshenieks MM, Sullivan JM, Twardowski MS (2002) Thin layers and camouflage: hidden Pseudo-nitzschia spp. (Bacillariophyceae) population in a fjord in the San Juan Island, Washington, USA. Mar Ecol Prog Ser 225:123-137

Rothschild BJ, Osborn TR (1988) Small-scale turbulence and plankton contact rates. J Plankton Res 10:465-474

Schooley AH, Stewart RW (1963) Experiments with a self-propelled body submerged in a fluid with a vertical density gradient. J Fluid Mech 15:83-96

Seuront L, Schmitt F, Lagadeuc Y (2001) Turbulence intermittency, small-scale phytoplankton patchiness and encounter rates in plankton: Where do we go form here? Deep-Sea Res I 48:1199-1215

Sherman JT, Davis RE (1995) Observations of temperature microstructure in NATRE. J Phys Oceanogr 25: 1913-1929

Siddon TE (1965) A turbulence probe utilizing aerodynamic lift. Note 88, Institute for Aerospace Studies, University of Toronto

Stacey MT, McManus MA, Steinbuck JV (2007) Conver-

Editorial responsibility: Alejandro Gallego, Aberdeen, UK gences and divergences and thin layer formation and maintenance. Limnol Oceanogr 52:1523-1532

Stockhausen PJ, Clark CB, Kennedy JF (1966) Three-dimensional momentum-less wake in density-stratified liquids. Tech Rep No 93, Hydrodynamics Lab, Massachusetts Institute of Technology, Cambridge, MA

Sullivan JM, Swift E (2003) Effects of small-scale turbulence on net growth rate and size of ten species of marine dinoflagellates. J Phycol 39:83-94

Sullivan JM, Twardowski MS, Donaghay PL, Freeman S (2005) Using optical scattering to discriminate particle types in coastal waters. Appl Opt 44:1667-1680

Tennekes H, Lumley JL (1972) A first course in turbulence. MIT Press, Cambridge, MA

Thorpe SA (2005) The turbulent ocean. Cambridge University Press, New York

Wolf KU, Woods JD (1988) Lagrangian simulation of primary production in the physical environment the deep chlorophyll maximum and nutricline. In: Rothschild BJ (ed) Towards a theory on biological-physical interactions in the world ocean. Kluwer, Dordrecht, p 51-70

- Woods JD (1968) Wave-induced shear instability in the summer thermocline. J Fluid Mech 32:791-800

Yamazaki H, Osborn T (1990) Dissipation estimates for stratified turbulence. J Geophys Res 95:9739-9744

Zaneveld JRV, Kitchen JC, Bricaud A, Moore C (1992) Analysis of in-situ spectral absorption meter data. Ocean Optics XI. In: Gilbert GD (ed) Proc SPIE 1750. SPIE, Bellingham, WA. Proc SPIE 1750:187-200

Submitted: April 2, 2008; Accepted: September 18, 2008 Proofs received from author(s): December 17, 2008 